Alexander Rausch • Björn R. Tammen (Hg.)

\title{
MUSIKALISCHE REPERTOIRES IN ZENTRALEUROPA (1420-1450)
}

Prozesse \& Praktiken

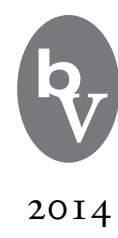

Böhlau Verlag Wien Köln Weimar 


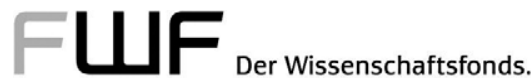

\section{Veröffentlicht mit Unterstützung des Austrian Science Fund (FWF): PUB 160-V21}

Bibliografische Information der Deutschen Nationalbibliothek:

Die Deutsche Nationalbibliothek verzeichnet diese Publikation in der Deutschen Nationalbibliografie; detaillierte bibliografische Daten sind im Internet über http://dnb.d-nb.de abrufbar.

Umschlagabbildung: Ulrich Richental, Chronik des Konstanzer Konzils, Papstweihe Martins V. (Detail). Österreichische Nationalbibliothek, Cod. 3044, fol. 128v. Foto: Bildarchiv, ÖNB/Wien

(C) 2014 by Böhlau Verlag Ges.m.b.H., Wien Köln Weimar

Wiesingerstraße 1, A-1010 Wien, www.boehlau-verlag.com

Alle Rechte vorbehalten. Dieses Werk ist urheberrechtlich geschützt.

Jede Verwertung außerhalb der engen Grenzen des Urheberrechtsgesetzes ist unzulässig.

Korrektorat: Nikola Langreiter und Janice Horton

Satz: Michael Rauscher, Wien

Druck und Bindung: Theiss, St. Stefan im Lavanttal

Gedruckt auf chlor- und säurefreiem Papier

Printed in the EU

ISBN 978-3-205-79562-9 


\section{INHALT}

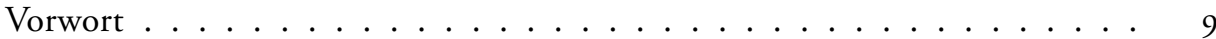

Abkürzungsverzeichnis . . . . . . . . . . . . . . . . Io

Björn R. Tammen

Von Prozessen und Praktiken, Schnittstellen und Schmelztiegeln,

Raumbefunden und musikalischen Repertoires. Anstelle einer Einleitung . . . I I

\section{GrundsätZLICHes}

Reinhard Strohm

Ritual - Repertoire - Geschichte: Identität und Zeitbewusstsein . . . . . . 2 I

Mehrstimmige Repertoires - Sammlungen \& Komponisten

Rudolf Flotzinger

Anlage und Herkunft des Trienter Codex 93 . . . . . . . . . . . . . 39

Ian Rumbold

Hermann Pötzlinger und seine Musiksammlung. Der Mensuralcodex

St. Emmeram als Zeugnis der zentraleuropäischen Musikpraxis um I440 . . . 65

Peter Wright

The Transmission of English Liturgical Music to Central Europe

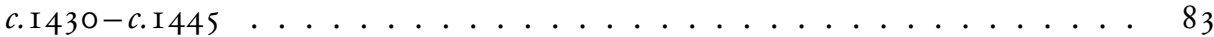

Alexander Rausch

Netzwerke lokaler Komponisten in Wien um I430 . . . . . . . . . I I 3

Paweł Gancarczyk

Presulem ephebeatum by Petrus Wilhelmi de Grudencz and the Musical Identity of Central Europe . . . . . . . . . . . . . . . . I35 
Mehrstimmige Repertoires - Kontexte \& Funktionen

Margaret Bent

"Libri de cantu" in the Early Fifteenth-Century Veneto: Contents, Use and

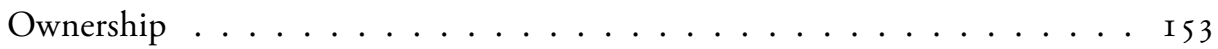

Wolfgang Fuhrmann

Subjektivierung von Polyphonie. Die Devotionsmotette im Kontext der

Gattungstransformation $\mathrm{I} 420-\mathrm{I} 450 \ldots \ldots \ldots$ I7I

Björn R. Tammen

Anverwandlungen vokaler Mehrstimmigkeit im Bild und durch das Bild.

Fallbeispiele aus der ersten Hälfte des I 5. Jahrhunderts . . . . . . . . . . 227

\section{Die einstimmige Liedkunst}

Ulrich Müller $(\dagger)$

Sangvers-Lyrik und Sangvers-Epik in deutscher Sprache. Überlegungen zum

musikalischen Repertoire im habsburgischen Zentraleuropa

im späten I 4. Jahrhundert und in der ersten Hälfte des I 5. Jahrhunderts . . . 253

Stefan Rosmer

Höfische Liedkunst im Kloster, in der Stadt und andernorts.

Zur Rezeption der geistlichen Lieder des Mönchs von Salzburg in der ersten

Hälfte des I 5 . Jahrhunderts . . . . . . . . . . . . . 27I

Marc Lewon

Die Liedersammlung des Liebhard Eghenvelder: im Ganzen mehr als die

Summe ihrer Teile . . . . . . . . . . . . . . . . . . . . . . . . . 299

Jenseits von musikalischen Repertoires

Susana Zapke

Musikalische Bildungs- und Ausbildungsprofile im Wissensraum Wien, I 5. Jahrhundert. Dokumente zu ihrer Erschließung . . . . . . . . . . 347 
ANHANG

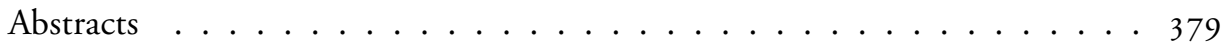

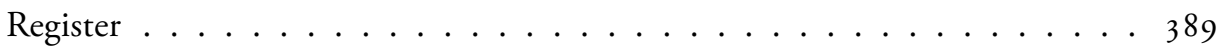

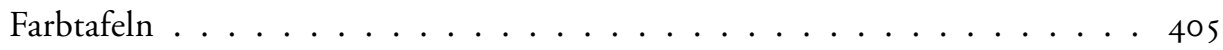

Autorinnen \& Autoren . . . . . . . . . . . . . . 4I3 



\section{Höfische Liedkunst im Kloster, in der Stadt und}

\section{ANDERNORTS}

Zur Rezeption der geistlichen Lieder des Mönchs von Salzburg in der ersten Hälfte des I 5. Jahrhunderts

\section{I. Überlieferung und Entstehung des Liedkorpus ,Mönch von SALZBURG}

In den 6oer und 7oer Jahren des I 5 . Jahrhunderts legte ein Skriptorium im bairischösterreichischen Sprachraum vier Handschriften mit über hundert geistlichen und weltlichen deutschsprachigen Liedern an. ${ }^{1}$ Dieses Korpus wird dort insgesamt dem ,Mönch von Salzburg' zugeschrieben. ${ }^{2}$ Die vier Handschriften aus demselben Skriptorium sind alle mit Notation versehen. Daneben tradieren vier weitere Handschriften ebenfalls aus der zweiten Hälfte des I 5 . Jahrhunderts eine größere Anzahl von Liedern des Mönchs, jedoch ohne Melodien. Ein Mönch-Korpus findet sich zudem innerhalb einer größeren Liedersammlung im Liederbuch der Clara Hätzlerin ${ }^{3}$ und

1 Mönch-Handschriften A (D-Mbs Cgm 715); B (D-Mbs Cgm 1115); D (A-Wn 2856, MondseeWiener Liederhandschrift); E (A-Wn 4696, Lambacher Liederhandschrift). Nachweis, dass die Handschriften aus demselben Skriptorium stammen, durch Karin Schneider in einer von BuRgharT WACHINGER, Der Mönch von Salzburg. Zur Überlieferung geistlicher Lieder im späten Mittelalter (Hermaea, Neue Folge 57), Tübingen 1989, 77-79 zitierten brieflichen Mitteilung. Sofern Handschriften in der Mönch-Forschung eine feste Sigle tragen, steht sie im Weiteren vor der RISM-Sigle.

2 Editionen: Die geistlichen Lieder des Mönchs von Salzburg, hg. von Franz Viktor Spechtler (Quellen und Forschungen zur Sprach- und Kulturgeschichte der germanischen Völker N.F. 51 [175]), Berlin etc. 1972 (zitiert für die Texte der geistlichen Lieder mit Angabe der Liednummer, Zählung G 1-G 49); Der Mönch von Salzburg. Die Melodien zu sämtlichen geistlichen und weltlichen Liedern, hg. von Hans Waechter/Franz Viktor Spechtler (Göppinger Arbeiten zur Germanistik 719), Göppingen 2004 (zitiert für die Melodien der geistlichen Lieder mit Liednummer und Seitenzahl); Die weltlichen Lieder des Mönchs von Salzburg. Texte und Melodien, hg. von Снгіsторн März (Münchener Texte und Untersuchungen zur deutschen Literatur des Mittelalters 114), Tübingen 1999 (zitiert für Texte und Melodien der weltlichen Lieder mit Angabe der Liednummer, Zählung W 1-W 57*). Faksimile der Hs. D: Mondsee-Wiener Liederhandschrift aus Codex Vindobonensis 2856, wissenschaftlicher Kommentar: Hedwig Heger (Codices Selecti 19), Graz 1968.

3 Mönch-Hs. H (CZ-Pn X A 12, ohne Melodien). Edition: Liederbuch der Clara Hätzlerin, hg. von Carl Haltaus (Bibliothek der gesammten deutschen National-Literatur 8), Quedlinburg-Leipzig 
in der Kolmarer Liederhandschrift. ${ }^{4}$ In drei dieser Handschriften erhält der Mönch einen Namen, allerdings verschiedene: „Herman "5 einerseits, „Hanns/Johanns“6 andererseits. Neben diesen zehn Sammelhandschriften steht eine Streuüberlieferung mit insgesamt I 3 I bekannten Handschriften und vier Frühdrucken vom späten I 4. bis ins I6. Jahrhundert. ${ }^{7}$ Die Sammelhandschriften bringen den Autor in Beischriften oder in Registereinträgen mit dem Salzburger Erzbischof Pilgrim II. in Verbindung, der von I 366 bis 1396 regierte. Dass die Lieder ursprünglich an den Hof Pilgrims gehörten, zeigt sich auch in den Texten: Das als Liebesbrief gestaltete Lied W 7 inszeniert Pilgrim als Verfasser, am Ende ist dieser Brief auf das Jahr I 392 datiert. Das geistliche Lied G 2 bildet das Akrostichon Pylgreim Erczpischof Legat, ein weiteres Akrostichon (G 3 ) nennt Richerus Plebanus in Rastat - Reicher war Pfarrer von Radstadt südlich von Salzburg und ist I 380 als Kaplan am Hof Pilgrims, I 384 als Hofmeister belegt. ${ }^{8}$

Zwischen der Entstehung der Lieder am Salzburger Hof und der Aufzeichnung in den Korpushandschriften der zweiten Hälfte des I 5. Jahrhunderts liegen gut siebzig Jahre. In den Korpushandschriften kann man insgesamt ein dezidiertes Interesse am Autor feststellen; neben anderem - beispielsweise dem Interesse an bestimmten Sprach- und Übersetzungsstilen ${ }^{9}$ - ging es den Sammlern und Redaktoren vor allem darum, die Lieder eben jenes ,Mönchs‘ zusammenzutragen und festzuhalten. Für die Streuüberlieferung lässt sich solch ein Interesse am Autor nicht ausmachen: Die Texte bleiben in ihr großteils anonym. ${ }^{10}$ Was waren dann in der ersten Hälfte des 15 . Jahr-

1840. Neudruck mit einem Nachwort von Hanns Fischer, Berlin 1966. Digitalisat: <http://www. manuscriptorium.com/apps/main/en/index.php? request=request_document $\&$ docId=rep_remake $160>$, 18.4.2011.

4 Mönch-Hs. K (D-Mbs Cgm 4997, mit Melodien). Faksimile: Die Kolmarer Liederhandschrift der Bayerischen Staatsbibliothek München (cgm 4997) in Abbildung, hg. von Ulrich Müller/Franz ViKTOR Spechtler/Horst Brunner (Litterae 35), Göppingen 1976.

5 Mönch-Hs. A (D-Mbs Cgm 715, fol. 6r).

6 Mönch-Hs. C (D-Mbs Cgm 628, fol. 253r); E (A-Wn 4696, fol. 107r). Abdruck der Namensnennungen bei Spechtler, Die geistlichen Lieder (wie Anm. 2), 9 f. und 39 (A), 46 (C), 51 (E), März, Die weltlichen Lieder (wie Anm. 2), 56 f. (A) und 74 (E). Zum Register der Hs. A vgl. WACHinger, Der Mönch von Salzburg (wie Anm. 1), 81-88, zu den Namensnennungen 119-127.

7 Zur Gesamtüberlieferung vgl. die Handschriftenbeschreibungen in SPEChtLER, Die geistlichen Lieder (wie Anm. 2), März, Die weltlichen Lieder (wie Anm. 2) und WACHinger, Der Mönch von Salzburg (wie Anm. 1), sowie die Zusammenstellung im Handschriftencensus. Eine Bestandsaufnahme der handschriftlichen Überlieferung deutschsprachiger Texte des Mittelalters, <http://www.handschriftencensus. de/werke/2056>, 18.4.2011.

8 Spechtler, Die geistlichen Lieder (wie Anm. 2), $15 \mathrm{f}$.

9 Vgl. Wachinger, Der Mönch von Salzburg (wie Anm. 1), 94.

10 Eine Nennung des Autors findet sich vor den Sammelhandschriften in nur vier Fällen. Es handelt sich bei den geistlichen Liedern um Mönch-Hs. S (D-Mbs Clm 14574, 1. Hälfte 15. Jahrhundert), „Der Münich item“" (Spechtler, Die geistlichen Lieder [wie Anm. 2], 63); D-Mbs Cgm 1019, Mitte 15. 
hunderts die Gründe dafür, Lieder vom Ende des vorigen Jahrhunderts aufzuzeichnen? In welchen Zusammenhängen stehen sie in den Handschriften und was sagt dies über die Verwendung der Lieder aus? Und stimmen die Gebrauchszusammenhänge im I 5. Jahrhundert mit denen an der Produktionsstätte überein? Diesen Fragen möchte ich exemplarisch anhand von drei geistlichen Liedern nachgehen. In der Forschung wurde bisher allerdings kein Konsens über den Gebrauchszusammenhang der geistlichen Lieder gefunden. Erwogen wurden - jeweils für einzelne Lieder und in erster Linie anhand der Übersetzungen im Mönch-Korpus - persönliche religiöse Erbauung und Andacht ${ }^{11}$, Verständnissicherung bei den Sängern ${ }^{12}$, stille Lektüre für Laien während des Gottesdienstes ${ }^{13}$, Rezeption innerhalb eines höfischen „gebildeten Kreises von Kennern" ${ }^{14}$ sowie Chor- oder Gemeindegesang ${ }^{15}$ innerhalb oder außerhalb der Liturgie. Ich gebe daher zuerst eine Skizze der soziokulturellen Hintergründe der Mönch-Lieder am Entstehungsort und versuche eine grobe Funktionszuweisung für das Gesamtkorpus.

Jahrhundert, „In des Münchß korweyß von Salczburg“ (Karin SchneIder, Die deutschen Handschriften der Bayerischen Staatsbibliothek München: Die mittelalterlichen Handschriften aus Cgm 888-4000, Wiesbaden ${ }^{2}$ 1991, 59 und 61); D-Mbs Cgm 351, 2. Viertel 15. Jahrhundert, ,in des minich von salczpurks don" (Spechtler, Die geistlichen Lieder [wie Anm. 2], 79; Karin Schneider, Die deutschen Handschriften der Bayerischen Staatsbibliothek München: Die mittelalterlichen Handschriften Cgm 351-500, Wiesbaden ${ }^{2} 1973$, 17). Bei den weltlichen Liedern findet sich eine Autornennung in der Sterzinger Miszellaneenhandschrift (Sterzing/Vipiteno, Stadtarchiv, ohne Signatur), 1. Jahrzehnt 15. Jahrhundert, „Münch vō sāl“ (März, Die weltlichen Lieder [wie Anm. 2], 123). In der späteren Streuüberlieferung finden sich weitere Autornennungen, wenngleich sie auch dort in der Minderzahl sind.

11 Andeutungsweise WACHINGER, Der Mönch von Salzburg (wie Anm. 1), 137, wobei er hier eher mit Lesen und betendem Sprechen als mit Gesangsvortrag rechnet. GüNTHER BärnTHALER, Übersetzen im deutschen Spätmittelalter. Der Mönch von Salzburg, Heinrich Laufenberg und Oswald von Wolkenstein als Übersetzer lateinischer Hymnen und Sequenzen (Göppinger Arbeiten zur Germanistik 371), Göppingen 1983.

12 Bärnthaler, Übersetzen im deutschen Spätmittelalter (wie Anm. 11); Ders., „Aufgaben und Probleme der Analyse spätmittelalterlicher Übersetzungen am Beispiel des geistlichen Liedes. Die Funktion des Übersetzens aus dem Lateinischen beim Mönch von Salzburg", in: Franz Viktor Spechtler (Hg.), Lyrik des ausgehenden 14. und des 15. Jahrhunderts (Chloe, Beihefte zum Daphnis 1), Amsterdam 1984, 29-44.

13 Bruno Quast, Vom Kult zur Kunst. Öffnungen des rituellen Textes in Mittelalter und Früher Neuzeit (Bibliotheca Germanica 48), Tübingen-Basel 2005, 141-166, für die Übersetzungen G 5 und G 47.

14 Ingo Reiffenstein, „Übersetzungstypen im Spätmittelalter. Zu den geistlichen Liedern des Mönchs von Salzburg", in: Spechtler (Hg.), Lyrik des ausgehenden 14. und des 15. Jahrhunderts (wie Anm. 12), 173-205, für Übersetzungen des Typus von G 7, Zitat 196.

15 Hans Waechter, Die geistlichen Lieder des Mönchs von Salzburg. Untersuchungen unter besonderer Berücksichtigung der Melodien (Göppinger Arbeiten zur Germanistik 724), Göppingen 2005; MAX Schiendorfer, „Drei Ostergesänge des Mönchs von Salzburg (G 29, 30 und 31) sowie zwei neue Quellenbelege zu Christ ist erstanden“, in: Beiträge zur Geschichte der deutschen Sprache und Literatur 116 (1994), 37-65. 


\section{Drei Lieder (G 3, G io, G 33) und der Salzburger Hof}

Betrachtet man das Gesamtkorpus von weltlichen und geistlichen Liedern, so zeigt sich eine beträchtliche Formenvielfalt: Unter den weltlichen Liedern finden sich deutsche Virelais ${ }^{16}$ und durchkomponierte Strophenlieder ohne Wiederholung musikalischer Blöcke, die Tenores ${ }^{17}$. Für diese Typen sind keine (Tenores) oder nur wenige (Virelais) Parallelen in der deutschsprachigen Liedkunst vor dem Mönch überliefert. ${ }^{18}$ Weiter gibt es bei den weltlichen Liedern zwei Typen von Mehrstimmigkeit: verschriftlichte usuelle Singpraktiken (W I-W 5, W $\left.55^{*}\right)^{19}$ und kunstgerechte ArsNova-Satztechnik in Gestalt einer Kontrafaktur einer französischen Chace (W 3I ${ }^{20}$. Bei den - allesamt einstimmigen - geistlichen Liedern lassen sich zunächst Übersetzungen lateinischer Hymnen und Sequenzen von den Eigendichtungen unterscheiden. Die Eigendichtungen unterscheiden sich nach ihrem Formvorbild: Sechs Lieder bilden die Form einer lateinischen Sequenz nach, ihr Text ist auf die Melodie der Sequenz zu singen. Dazu stellt sich das abecedarische Prunkstück G I, das sequenzartig gebaut ist, zu dem aber keine Melodievorlage bekannt ist. Neun Lieder sind in großen, stollig gebauten Strophen verfasst (also musikalisch AAB), wie man sie aus Sangspruchdichtung und meisterlicher Liedkunst kennt. Vier dieser Lieder stimmen in ihrem metrischen Schema und ihrem Reimschema mit älteren deutschen Texten überein : ${ }^{21}$ G 12 entspricht dem Minnelied Mich jâmert ûz der mâze Wernhers von Hohenberg ${ }^{22}$ und drei anonym überlieferten Sangsprüchen ${ }^{23}$, G 20 und G 38 sind

16 Die Virelais des Mönch-Korpus haben keinen Refrain vor der ersten Strophe, weswegen auch andere Benennungen für sie verwendet wurden. Ich schließe mich der Terminologie von MäRz, Die weltlichen Lieder (wie Anm. 2) an; die Entscheidung für Virelai statt Ballade als Oberbegriff ist ebda., 19-27, 24 begründet.

17 Die Terminologie wiederum nach März, Die weltlichen Lieder (wie Anm. 2), 14-19.

18 Ebda. 14 (Anm. 22) und 27-30.

19 Vgl. Christoph März, Art. „Mönch von Salzburg“, in: MGG2, Personenteil 12 (2004), 333-336.

20 Vorlage im Codex Ivrea: Umblemens vos pri merchi (I-IV 115, fol. 58v-59r), siehe März, Die weltlichen Lieder (wie Anm. 2), $94 \mathrm{f}$.

21 Die metrisch-reimtechnischen Übereinstimmungen könnten durch die Übernahme der Melodien bedingt sein, mit der der gesamte ,Ton' (zur Definition vgl. Johannes Rettelbach, Variation - Derivation - Imitation. Untersuchungen zu den Tönen der Sangspruchdichter und Meistersinger [Frühe Neuzeit 14], Tübingen 1993, 44-49) als Einheit von Metrum, Reimschema und Melodie übernommen wurde.

22 Die Schweizer Minnesänger. Nach der Ausgabe von Karl Bartsch neu bearb. und hg. von Max SchienDorfer, Bd. 1 : Texte, Tübingen 1990, 12 (Nr. 2, 4,I). Nachweis der Tonidentität durch Gisela KornRUMPF in WaChinger, Der Mönch von Salzburg (wie Anm. 1), 127.

23 Gisela Kornrumpf, „Drei unbekannte Sangsprüche des 13. Jahrhunderts“, in: Helmut Engelhart (Hg.), Der St. Marienthaler Psalter, Regensburg 2006, 79-87, 87. Bereits Retтelbach, Variation - 
formal mit dem Minnelied Seht an die heide Gottfrieds von Neifen identisch ${ }^{24}$, das lateinische Lied G 9 und seine deutsche Vorlage Maria gnuchtig zuchtig von Peter von Sachsen ${ }^{25}$ gehen vermutlich auf das Lied Man siht lovber zurück. ${ }^{26}$ Fünf der geistlichen Lieder bestehen aus formal einfacheren Strophen. ${ }^{27}$

Betrachtet man das Gesamtkorpus, so zeigt sich, dass unterschiedliche Gattungen und Traditionen musikalischer Lyrik aufgegriffen und produktiv umgeformt wer$\mathrm{den}^{28}$; allen Typen gemeinsam ist die Verwendung des Deutschen. Deutschsprachige Lieder in solch vielgestaltiger Form - Virelais, Tenores, Sequenzen, Lieder in stolligen und in kleinen Strophen, mehrstimmige Experimente und avancierte Mehrstimmigkeit französischer Provenienz - an ein und demselben Ort: Auch wenn die ungünstige Überlieferungslage das Urteil erschwert, dürfte es dies gegen Ende des I4. Jahrhunderts nur in Salzburg gegeben haben, am ,Liederhof' Pilgrims II. Hier zeigt eine Hofgesellschaft höchste Kompetenz in der Kenntnis und Produktion von Liedern.

Die historische Forschung zeichnet von Pilgrims Salzburger Hof ein Bild, in dem sich solch ein Bestreben situieren lässt: ${ }^{29}$ Finanziell und wirtschaftlich war Pilgrim

Derivation - Imitation (wie Anm. 21), 179 f., hatte angenommen, dass die Kenntnis des ,Tons ' nicht direkt vom Minnelied Wernhers herrühren könne.

24 Deutsche Liederdichter des 13. Jahrhunderts, hg. von Carl von Kraus, 2. Aufl. durchgesehen von Gisela KornrumpF, Bd. 1: Text, Tübingen 1978, 102-104 (Nr. 15,XX). Nachweis der Tonidentität in Dies., „Rezension zu Walter Röll, Vom Hof zur Singschule. Überlieferung und Rezeption eines Tones im 14.-17. Jahrhundert", in: Anzeiger für deutsches Altertum und deutsche Literatur 108 (1979), 14-22; vgl. Rettelbach, Variation - Derivation - Imitation (wie Anm. 21), 158.

25 Siehe dazu Spechtler, Die geistlichen Lieder (wie Anm. 2), 18 und $369 \mathrm{f}$.

26 Dazu KornrumpF, „Rezension“ (wie Anm. 24) und Gisela KornrumpF, Art. „Peter von Sachsen“, in: ${ }^{2} V L 7$ (1989), 452-454.

27 Wachinger, Der Mönch von Salzburg (wie Anm. 1), 127-130, nimmt aufgrund der Analyse der Überlieferungslage an, dass G 22, G 24 und G 46 erst in der Überlieferung dem Mönch-Korpus hinzugefügt wurden. Es bleiben aber dennoch zwei geistliche Lieder in einfachen Strophen, bei denen die Autorschaft der Mönchs unstrittig ist: Tischsegen (G 42) und Cisiojanus (G 45).

28 Zum Gattungssystem des Mönch-Korpus vgl. auch Burghart WaChinger, „Textgattungen und Musikgattungen beim Mönch von Salzburg und bei Oswald von Wolkenstein“, in: Beiträge zur Geschichte der deutschen Sprache und Literatur 132 (2010), 385-406, 386-391.

29 Vgl. zum Folgenden Herbert Klein, „Erzbischof Pilgrim II. von Puchheim (1365-1396)“, in: Mitteilungen der Gesellschaft für Salzburger Landeskunde 112/113 (1972/73), 13-71; SPECHTLER, Die geistlichen Lieder (wie Anm. 2), 18-25; Heinz Dopsch (Hg.), Geschichte Salzburgs. Stadt und Land, Bd. 1: Vorgeschichte, Altertum, Mittelalter, Salzburg 1981; Peter F. Kramml, „Pilgrim II. von Puchheim (1366-1396)“, in: Peter F. Kramml/Stefan Weiss (Hgg.), Lebensbilder Salzburger Erzbischöfe aus zwölf Jahrhunderten. 1200 Jahre Erzbistum Salzburg (Salzburg Archiv 24), Salzburg 1998, 101-122; Heinz Dopsch, Art. „Salzburg, Erzbischöfe von [...]“, in: Werner Paravicini (Hg.), Höfe und Residenzen im spätmittelalterlichen Reich. Ein dynastisch-topographisches Handbuch (Residenzenforschung 15.1), Teilband 1: Dynastien und Höfe, Ostfildern 2003, 484-495; Christian Schneider, Hovezuht. Literarische Hofkultur und höfisches Lebensideal um Herzog Albrecht III. von Österreich und 
erfolgreich, seine Hofhaltung gilt als auf die Repräsentation seines Machtanspruchs ausgerichtet. Diese war für den Salzburger Hof sowohl aufgrund seiner diplomatischen Kontakte nach Avignon und Prag als auch innerhalb Salzburgs wichtig, denn Pilgrim musste seinen Herrschaftsanspruch gegen Teile des Domkapitels und gegen den Stadtadel durchsetzen. Auch wenn dem Bischofshof Kleriker und Laien angehörten, war er in seinem engeren Zirkel klerikal dominiert. Die consiliarii, die den Erzbischof bei der Regierung am Hofgericht unterstützten, waren überwiegend Kleriker - daneben gab es auch einige Laien aus Ministerialenfamilien und aus Herrengeschlechtern -, die Mitglieder der Hofkanzlei waren ausschließlich Geistliche, und auch das Amt des Hofmeisters war zu Pilgrims Regierungszeit nur mit Geistlichen besetzt. Es handelte sich also um einen Hof, an dem es an Lateinkenntnissen nicht gemangelt haben dürfte. Von dieser Seite her betrachtet lassen sich die Lieder in ihrer Gesamtheit sehr gut im Kontext höfischer Repräsentation verorten. Ihre Typenvielfalt stellte im deutschsprachigen Umfeld etwas Besonderes, ja Einmaliges dar. Mit ihnen konnte sich der Hof nach außen als einzigartiger Ort literarisch-musikalischen Kunstsinns erweisen und dadurch Vornehmheit und soziokulturellen Führungsanspruch bekräftigen.

Richtet man den Blick auf die Faktur der geistlichen Lieder, dann signalisieren sie solche Exklusivität durch ihre gekonnte dichterische Ausführung - ihre Sprachartistik - und zudem durch ein gewisses Maß an Gelehrtheit. Neben ihrer repräsentativen Funktion nach außen konnten sie damit nach innen der Vergewisserung des eigenen Status und der eigenen Vornehmheit dienen. Was unter Sprachartistik und Gelehrtheit im Detail zu verstehen ist und wie die Funktionen Repräsentation und Selbstbestätigung möglicherweise erfüllt wurden, sei an drei Liedern verdeutlicht.

\section{G3-Richer schatz der höchsten freuden}

Die sub-melodia-Dichtung (im Anschluss an die Überschriften in Korpushandschrift F bezeichnet man mit sub melodia Texte, die nicht übersetzt sind, aber Melodie und Strophenform einer lateinischen Vorlage verwenden) trägt das Akrostichon Richervs plebanvs in Rastat, Melodie und Aufbau sind durch die Vorlage, die Sequenz Salve, mater salvatoris, festgelegt. Deren metrisch-musikalische Vorgaben sind genau erfüllt, nur an zwei Stellen, im zweiten Halbversikel der Versikel III und VIII, weicht der deutsche Text in Silbenzahl und Kadenz vom lateinischen ab. Man könnte diese Abweichungen auch so verstehen, dass G 3 gewissermaßen genauer ist als sein lateini-

Erzbischof Pilgrim II. von Salzburg (1365-1396) (Beiträge zur älteren Literaturgeschichte), Heidelberg 2008, 71-90. 
sches Formvorbild: ${ }^{30}$ Der zweite Halbversikel der Versikel III und VIII bei Salve, mater salvatoris ist nämlich nicht mit dem jeweils ersten identisch. Der erste Halbversikel hat in den ersten beiden Versen acht Silben pro Vers und einen paroxytonischen Versschluss, der zweite dagegen nur sieben Silben und eine proparoxytonische Kadenz. ${ }^{31}$ Gegenüber der lateinischen Vorlage bildet G 3 den zweiten Halbversikel jeweils exakt dem ersten nach: Dem achtsilbigen Paroxyton entspricht im Deutschen ein Vierheber mit weiblichem Versschluss, das Schema für Strophe III und VIII lautet (, | 'trennt Halbversikel): 4w, 4w, 3m | 4w, 4w, 3m, für Salve, mater salvatoris dagegen: 8po, 8po, 7ppo | 7ppo, 7ppo, 7ppo. In G 3 kann daher die Melodie exakt wiederholt werden. ${ }^{32}$ Auch syntaktisch schließt G 3 an das lateinische Formvorbild an. Noch stärker als in der lateinischen Sequenz sind die beiden Halbversikel inhaltlich und syntaktisch immer deutlich voneinander abgesetzt, so dass mit jedem geschlossenen Abschnitt der Melodie eine eigenständige Aussage verbunden ist. Trotz der engen Anlehnung an die Vorlage wirkt der Text von $\mathrm{G} 3$ vollkommen ungezwungen: Nie spürt man Reimnot, der strikt alternierende Versgang erzeugt keine Füllsel. Gegenüber dem Prätext sind als zusätzlicher Schmuck Mittelreime (VI,3 I, 32, 34, 35) und die Figur des Polypto-

30 Von Salve, mater salvatoris gibt es im Mönch-Korpus zwei Übersetzungen: G 7 und G 8. In SpechtLER, Die geistlichen Lieder (wie Anm. 2), ist der Text der lateinischen Sequenz bei G 7 und G 8 abgedruckt nach den Analecta hymnica: Liturgische Prosen des Übergangsstils und der zweiten Epoche, hg. von Clemens Blume/Henry Marriott Bannister (Analecta hymnica medii aevi 54), Leipzig 1915, 383-386, Nr. 245. Die Melodie zum Salve, mater salvatoris ist abgedruckt in WAECHTER/SPECHTLER, Die Melodien (wie Anm. 2), S. 63-69, nach dem Moosburger Graduale (D-Mu, $2^{\circ}$ cod. ms. 156, fol. 216v-217v; Faksimile: Moosburger Graduale. München Universitätsbibliothek, $2^{\circ}$ Cod. ms. 156. Faksimile mit einer Einleitung und Registern von DAvid Hiley [Veröffentlichungen der Gesellschaft für Bayerische Musikgeschichte], Tutzing 1996).

31 Textmetrisch sind die Versikel III und VIII identisch, sie sind aber auf eine unterschiedliche Melodie zu singen. Die Analecta hymnica zählen drei- bzw. vierzeilige Strophen durch. Eine andere Versikelaufteilung bei PAul KLOPSCH (Hg.), Lateinische Lyrik des Mittelalters (Reclams Universal Bibliothek 8088), Stuttgart 1985, 296-301. Die Versikelabgrenzung wie bei G 7 (SpechtLer, Die geistlichen Lieder [wie Anm. 2], 154-160) entspricht den Wiederholungsstrukturen der Melodie. Das Moosburger Graduale löst das Problem der fehlenden Silbe im zweiten Halbversikel melodisch, indem der überzählige Ton einem folgenden oder vorangehenden Melisma zugefügt wird oder indem am Versschluss ein Ton entfällt.

32 Waechter/Spechtler, Die Melodien (wie Anm. 2), 40-43 (Melodie nach Hs. D; A-Wn 2856). Im Fall der Übersetzung G 7 des Salve, mater salvatoris, die der Vorlage besonders eng folgt (vgl. ReIFFENSTEIN, „Übersetzungstypen im Spätmittelalter“ [wie Anm. 14], 182-193), wird in Versikel III die Form der Vorlage beibehalten, in Versikel VIII gegen die Vorlage die exakte Wiederholung des zweiten Halbversikels wie in G 3 gewählt. G 8 geht mit der Vorlage insgesamt freier um, aber auch dort ist in Versikel III die Vorlage genau nachgebildet, in Versikel VIII metrisch umgeformt. G 7, III und G 8, III zeigen also, dass der Dichter in der Lage war, der Vorlage genau zu folgen, daher werden die beiden Abweichungen in G 3 wohl bewusst gewählt sein. 
ton (I,5; III, I, 2; IV,2 I ; XI,63, 66, 70) eingearbeitet. Artifizialitätsmerkmal ist auch das Akrostichon, das zudem in seinen ersten beiden Silben mit dem ersten Wort des Liedes übereinstimmt (Richer schatz [...] - RICHERUS PLEBANUS [...]).

Für eine Zuhörerschaft, die das Repertoire gottesdienstlicher Gesänge kannte, hat die erklingende Sequenz-Melodie sicher den lateinischen Text wachgerufen. Beim Hören des neuen deutschen Textes konnte der Zuhörer die lateinische Vorlage erinnern und die gekonnte Übernahme der Form ebenso goutieren wie die durchaus kunstfertigen Veränderungen. ${ }^{33}$ Für die kompetente Rezeption war also poetischer Sachverstand gefordert.

Inhaltlich zeigt sich ein Arrangement aus traditionellen Elementen der Mariendichtung, die zu einer zwar unauffälligen, aber doch stringenten Progression verknüpft sind. An ein erstes allgemeines Lob schließen sich in II-V heilsgeschichtliche Fakten in lockerer chronologischer Folge an (II: Eva, Verlust der Heils; III: Gruß Gabriels, Empfängnis; IV: Schwangerschaft Mariens; V: Maria bekleidet Gott als Mensch, Maria lactans). Die Versikel VI-IX betonen die Wirkmächtigkeit der Fürsprache Mariens bei Christus, wobei Maria durchweg die Apostrophierte ist; nur in VIII richtet sich der Imperativ - allerdings nach wie vor im Singular - an das Publikum. ${ }^{34}$ Nach einem allgemeinen Lob (Edelstein- und Pflanzenvergleiche) mündet der Schlussversikel XII in eine als Zitat wiedergegebene Fürsprache Mariens bei Christus. Das Ende des diesseitigen Lebens des Menschen steht am Ende des Textes, der entlang der Heilsgeschichte fortschreitet.

\section{G 10 - Maria keusche muter zart und $G 33$ - Kum senfter trost heiliger geist}

Inhaltlich verhält es sich in diesen Liedern ganz ähnlich. G Io setzt mit einer Anrede Mariens ein, situiert die Sprechsituation in der Heiligen Nacht (I,9) und betrachtet Erwählung Mariens, Empfängnis und Geburt (II,27-35). Dann folgen eine Reihe alttestamentlicher Präfigurationen Mariens (II,36-IV,92) und Verweise auf die Apokalypse (III,75-78), Baarlam-Legende (IV,87) und die drei Weisen (IV,89), was in die

33 Zum Rezeptionsmodus des vergleichenden Erinnerns siehe ChrIstoph MärZ, „Pange lingua per omnia verbo et melodia. Zu den Anfängen poetischer Hymnennachbildung in deutscher Sprache", in: Andreas Haug u. a. (Hgg.), Der lateinische Hymnus im Mittelalter: Überlieferung - Ästhetik - Ausstrablung (Monumenta Monodia Medii Aevi. Subsidia 4), Kassel etc. 2004, 279-299, zur Übertragung G 43 des Hymnus Ut queant laxis.

34 An einem klerikal geprägten Hof mochte es besonders gut passen, dass die Publikumsapostrophe in Zusammenhang mit Theophilus erfolgt. Der Theophilus der Legende ist - wie der Personenkreis am Salzburger Hof - als Priester Teil des Klerus. Auch er, als Kleriker, ist nicht vor dem Teufel gefeit und paktiert mit ihm, wird aber von Maria gerettet (G 3, X,48). Vgl. Konrad Kunze/Hansjürgen Linke, Art. „Theophilus“, in: ${ }^{2} V L 9$ (1995), 775-782. 
breiter ausgeführte Geburt in Bethlehem mündet (IV,94-Ioo). Die letzte Strophe (V) gilt wiederum ganz der Bitte um Beistand und Fürsprache.

G 33 beginnt ebenfalls mit einer Apostrophe, nun an den Heiligen Geist, und einer Bitte um die sieben Gaben (I,3-I4). Im Weiteren werden das Wesen des Heiligen Geistes innerhalb der Trinität und seine Rolle bei der Schöpfung (I, I 5-26), sein Wirken im Kosmos (II,27-40), in der Heilsgeschichte (III,53-IV,86) sowie in Gegenwart und Zukunft der Kirche und des Beters dargelegt, wobei er als Lehrer und wie Maria als Beistand beim Jüngsten Gericht angesprochen ist (II,43-52; IV,93-V, I30). Auch hier steht am Ende die Hoffnung, ewige Seligkeit durch Fürsprache des Heiligen Geistes zu erlangen (V, I27). Der geraffte Durchgang zeigt, dass die Texte ein Spektrum religiöser Wissensbestände auffächern und in den Lobpreis der Gottesmutter bzw. des Heiligen Geistes einbeziehen.

Formal handelt es sich bei G ro und G 33 um stollige Strophenlieder; beide sind auf dieselbe Melodie zu singen. Die Vorgabe der Kanzonenform ist variiert, indem der Abgesang selbst wieder stollig gebaut ist - man kann von einer Kanzone mit repetiertem Steg sprechen ${ }^{35}$-, wobei die Teile des Abgesangs gleich lang sind. Sprachlich aufwendig ist zunächst der Reim: Die ersten sechs Verse des Stollens reimen und der dreiteilige Abgesang hat einen neunfach wiederholten Reimklang. G 33 glänzt in den ersten vier Strophen zusätzlich durch zahlreiche anaphorische Versanfänge (I,5-I 2; II,36-39; III,6I-64; IV,94-99). Die Syntax orientiert sich ziemlich streng an den Strophenteilen, so dass zumeist ein Satz auf einen Stollen oder Abgesangsteil kommt.

Die Melodie (siehe Notenbeispiel) befestigt diese klare Gruppenbildung. Sie konstituiert ebenfalls klare Blöcke für jeden Strophenteil, indem der Beginn eines Formteils deutlich markiert wird: Der Beginn des Stegs ist gegenüber dem Stollen, der auf $a$ endet, mit einem Quintschritt abwärts und aufwärts ( $a-d-a)$ markiert, der sich weiter zum $c$ ' aufschwingt. Er endet - mit einem kleinen Schlussmelisma versehen - auf der Finalis $d$, so dass bei der Repetition des Stegs erneut hoch angesetzt wird. So setzt auch der dritte Abgesangsteil an, vom a steigt die Melodie innerhalb der Melodiezeile schrittweise zum Spitzenton $d$ ' auf. ${ }^{36}$ Die einzelnen Melodiezeilen/Verse bilden im-

35 Terminologie nach Rettelbach, Variation - Derivation - Imitation (wie Anm. 21), 10 f. Zum Zusammenhang mit dem Begriff ,Barform': Ders., Art. „Barform“, in: $M G G 2$, Sachteil 1 (1994), 1219_ 1227.

36 Die Melodiestrophe von G 10 endet in Hs. A (D-Mbs Cgm 715) auf $a$, nicht auf $d$ wie in Hs. D (Waechter/Spechtler, Die Melodien [wie Anm. 2], 76-78, 78), wobei es sich wohl um ein Versehen handelt: Der Schreiber hat die Melodie der Schlusszeile des Stollens (Z. 14) eingetragen statt jene der Schlusszeile des Abgesangs (Z. 26). Die Ursache könnte Folgendes gewesen sein: Die vorletzte Zeile des Stollens (Z. 13) endet in Hs. A mit dem Melisma $c-B-A$ und die letzte Stollenzeile beginnt mit dem Melisma $f-e-d$. Auch die vorletzte Zeile des Abgesangs (Z. 25) endet auf dasselbe Melisma $c-B-A$ und die letzte beginnt ebenfalls mit $f-e-d$. Da die Stollenwiederholung ausnotiert ist, findet sich also 

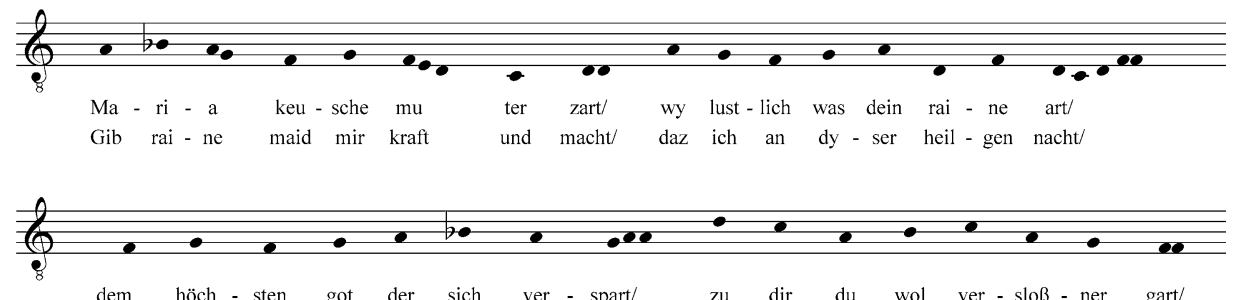

10 dein iunk - fräu - lich ge - purd be - tracht/ wy sich dein va - ter in dich flacht/
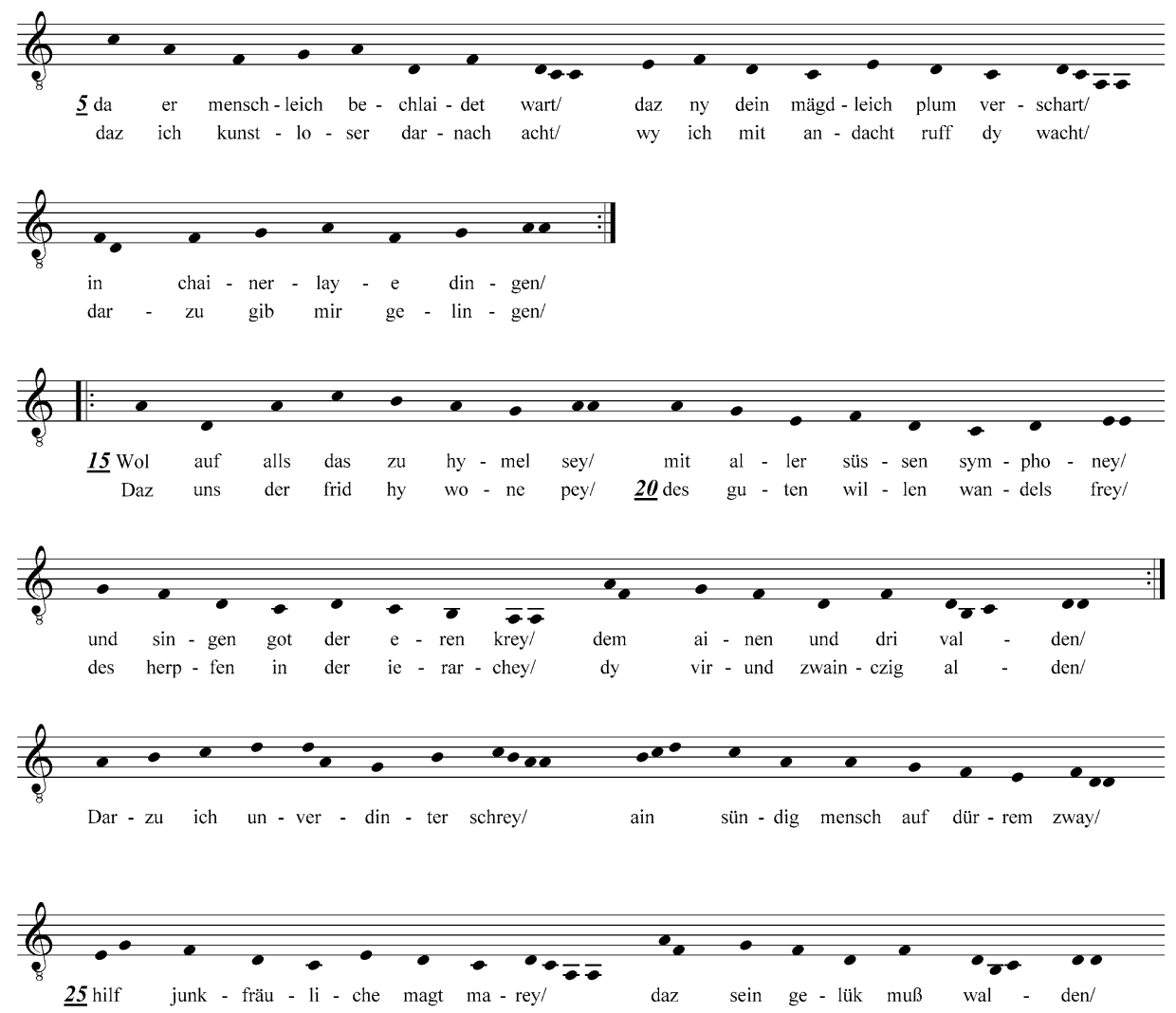

Notenbeispiel: Mönch von Salzburg, Maria keusche muter zart (G Io), I. Strophe;

Melodieüberlieferung und Text nach Hs. D 
mer einen für sich sinnvollen Satzteil und eine relativ selbstständige Aussage. Harte Enjambements, bei denen man sich den Wortlaut von Einzelversen über mehrere Melodiezeilen hinweg präsent halten muss, um Sinn und logische Struktur eines Satzes zu verstehen, werden vermieden, der Gleichlauf von Vers, Syntax und Melodie gerät in beiden Liedern nur an zwei Stellen außer Tritt. ${ }^{37}$

Der Effekt, dass wie bei G 3 die beträchtliche formale Durcharbeitung der Strophen fast nicht auffällt, rührt nicht zuletzt daher. Die Wirkung beim Hören ist eher die eines gleichmäßigen Mitverfolgens und Entschlüsselns des Textsinns. Ein gewisses $\mathrm{Ma}$ an religiöser Sachkenntnis setzen die Lieder aber an einigen Stellen doch voraus. Dass in G 33 die unterschiedlichen Bereiche, in denen der Heilige Geist wirksam ist, als Siebener-Listen miteinander verbunden sind ${ }^{38}$, erschließt sich wohl leichter und schneller, wenn man diese vorher schon kennt, zumal bei einer hörenden Rezeption. Die zahlreichen Verweise auf das Alte Testament in G Io sind so gestaltet, dass beispielsweise eine Präfiguration Mariens nur als Lobpreis genannt und nicht erklärt wird. Das Formulierungsmuster ist also ,Du, Maria, bist die Rute

dreimal die gleiche, im Schriftbild markante Zeilenverknüpfung (vgl. D-Mbs Cgm 715, fol. 154v, 1. System; fol. 155r, 2. System; fol. 156r, 2. System), so dass der Schreiber eventuell in seiner Vorlage auf die frühere, identisch aussehende Stelle zurückgesprungen ist. In Hs. D stehen andere Melismen $(d-c-A$ und $f-d)$, aber auch hier handelt es sich dreimal um dieselbe Zeilenverknüpfung. In der Aufzeichnung von G 33 ist in Hs. A die Schlusszeile, die zur Finalis $D$ führt, eingetragen, dort fehlt aber in der vorletzten Melodiezeile des Abgesangs im Gegensatz zu den Stollen das optisch charakteristische Melisma (D-Mbs Cgm 715, fol. 162v, 1. System und fol. 163r, 1. System, aber fol. 163v, 6. System).

37 G 10, II,34-35 und G 33, I,15-19. An der ersten Stelle ist der Übergang noch vergleichsweise glatt: Dass das Objekt zu einem Prädikat erst im folgenden Vers steht, ist nicht ungewöhnlich, allein der angeschlossene Relativsatz würde in einer anderen Konstellation einen eigenständigen Vers erhalten. Bei der zweiten Stelle scheint mir der Text insgesamt problematisch. Zumindest würde ich hinter die neuhochdeutsche Paraphrase der Verse G 33, I, 15-20 ein Fragezeichen setzen: , In dem Maße wie (Als) Gott im Anbeginn Höhe, Tiefe, Licht, Finsternis, Weite und Enge schuf, war der Sohn der Anfang aller Anfänge. Um mit seiner Hand alle Formen zu machen, gestaltete er Kürze und Länge'. Dass Gott Höhe und Tiefe schafft, der Sohn zwecks Formgebung Länge und Kürze, scheint mir keinen rechten Sinn zu geben. Bezieht man „er“ in G 33, I,19 auf Gottvater und fasst I,17 als Parenthese auf, gewinnt man für den Sinn nichts und die Aussage über den Sohn bleibt ganz ohne Zusammenhang. Korpushandschrift A (D-Mbs Cgm 715, fol. 163r) setzt in G 33, I,19 „aller form“ als Genitivattribut zu „kürz und leng“, beendet damit den Satz nach I,18 und tilgt so das Enjambement, nimmt dafür aber nicht nur den doppelten Auftakt in Kauf, sondern auch, dass in I,18-19 dem "machen“ das Objekt fehlt. Vielleicht liegt ein verderbter Text vor, die Überlieferung bietet aber keine ausreichenden Anhaltspunkte für eine überzeugende Emendation.

38 Sieben Gaben (G 33, I,5-12), siebenfache Art von Zeugnis: Heilige Schrift, Propheten, Apostel, Märtyrer, Bekenner, heilige Jungfrauen, Einsiedler (G 33, III,53-66), sieben Sakramente (G 33, III,6876), apokalyptische Siebenerreihen: Leuchter, Geister, Sigel, Gemeinden (G 33, IV,79-87), Sieben Freie Künste (G 33, IV,93-100). 
Aarons' oder ,Du, Pforte Ezechiels, hilf ...' und nicht ,Die Rute Aarons bedeutet Dich, Maria, weil ...' Dieses Formulierungsmuster war den gebildeten Rezipienten aus der lateinischen liturgischen Poesie gut vertraut, in Marienhymnen lassen sich hier dann freilich in Latein - zahlreiche solche Formulierungen finden. ${ }^{39}$ Hier wie dort aber galt, dass man die Auslegungstradition kennen musste, wenn man den Sinn des Textes vollständig entschlüsseln wollte - was man gleichwohl nicht in jedem Fall tun musste.

Dem heutigen philologisch bewanderten Leser, der die Hinweise des Herausgebers und andere Hilfsmittel ${ }^{40}$ parat hat, mögen diese Verweise etwas trivial oder in ihrer Serialität beliebig erscheinen. Stellt man sich aber eine hörende Rezeption des Gesangsvortrags durch kundige Rezipienten vor, dann eröffneten diese Verweise beim Hören einen Assoziationsraum - dies allerdings nur für den, der erkannte, worauf verwiesen wurde. Ein eingehendes Verständnis der Texte war daher wohl nur vor dem Hintergrund der Formulierungstraditionen und der jeweiligen Wissensbestände möglich.

Dennoch bieten die Texte von ihrer Faktur her auch die Option, dass sich das Verständnis auf die Kernaussage oder besser auf die Kernfunktion - Lobpreis und Anbetung Mariens bzw. des Heiligen Geistes - beschränkte, denn dieser Textsinn wird auch deutlich, wenn man nicht jede einzelne Formulierung entschlüsselt. Die Texte kommen dem insofern entgegen, als sie Sachverhalte nie durch die Art des Ausdrucks zusätzlich verrätseln. Das Maximum an Schwierigkeit sind Formulierungen wie G ıo, IV,8o-8 I : Maria umfängt das Wort, das die Enden der Himmel umfasst. Der Sinn solcher Formulierungen erschließt sich stets rasch, indem man sich die intendierte Referenz von wort vergegenwärtigt (das wort ist Christus, Christus ist Gott, Gott ist Träger/Erhalter des Himmels). Ein erklärender Duktus lässt sich in den geistlichen Eigendichtungen im Mönch-Korpus - auch in den drei sprachkünstlerisch und von der Strophenform her anspruchsloseren Liedern G 22, G 24 und G 46 - nicht ausmachen. Anzutreffen wäre er dagegen innerhalb der deutschsprachigen Literatur in der älteren Sangspruchdichtung, deren Strophenform die neun stolligen Lieder aufgreifen. Die Behandlung geistlicher Themen in der Sangspruchdichtung diente zumeist

39 Ein Beipiel: Analecta hymnica medii aevi, Bd. 4: Liturgische Hymnen des Mittelalters aus handschriftlichen Breviarien, Antiphonalien und Processionalien, hg. von Guido Maria Dreves, Leipzig 1888, 37 , Nr. 47 (Datierung der Handschrift im Band: 12. Jahrhundert): Maria angesprochen als „Summi regis mater", ,stella maris“, „porta coeli“, „sponsa Domini“.

40 Zum Beispiel Anselm Salzer, Die Sinnbilder und Beiworte Mariens in der deutschen Literatur und lateinischen Hymnenpoesie des Mittelalters, mit Berücksichtigung der patristischen Literatur. Eine literarhistorische Studie, Linz 1893 (Nachdruck Darmstadt 1967). 
der Wissensvermittlung ${ }^{41}$, was bei den Mönch-Liedern eher nicht das Ziel gewesen sein dürfte.

Die geistlichen Eigendichtungen im Mönch-Korpus erweisen sich, zusammenfassend charakterisiert, als formal und rhetorisch hochgradig durchgebildet und als vollständig wertzuschätzen nur mit Kenntnis und im Rückgriff auf in ihnen aktualisierte inhaltliche und formal-poetische Traditionsvorgaben. Dabei aber meiden sie schwer Verständliches, Rätselhaftes oder theologisch Umstrittenes. Man könnte sie von ihrer Faktur her als am rhetorischen Stilideal der claritas/perspicuitas ausgerichtet bezeichnen. ${ }^{42}$

Von diesem Zwischenfazit aus ist nun noch einmal kurz die Funktion am Salzburger Hof zu bedenken. Betrachtet man die Textfaktur, stehen die Texte für unterschiedliche Rezeptionshaltungen und Verwendungen offen. ${ }^{43}$ Dass die Lieder im Zusammenhang höfischer Repräsentation zu sehen sind, habe ich oben anhand der Typenvielfalt aller Lieder zu begründen versucht. Die geistlichen Eigendichtungen konnten diese Funktion meines Erachtens erfüllen, indem sie poetisch-technische wie theologisch-sachliche Kennerschaft demonstrierten. Der engere, klerikal dominierte Zirkel zeigte damit Kompetenz nach außen und versicherte sich dieser ein Stück weit selbst. Gegenüber weniger kundigen Zuhörern schlossen sich die Texte aber nicht hermetisch $\mathrm{ab}$, sondern hielten einen unmittelbar erfassbaren Verständnishorizont

41 Vgl. Helmut Tervooren, Sangspruchdichtung (Sammlung Metzler 293), Stuttgart 22001, 49-60; Klaus Grubmüller, „Autorität und meisterschaft. Zur Fundierung geistlicher Rede in der deutschen Spruchdichtung des 13. Jahrhunderts“, in: Peter Strohschneider (Hg.), Literarische und religiöse Kommunikation in Mittelalter und Früher Neuzeit. DFG-Symposion 2006, Berlin-New York 2009, 689-711. Vorbilder für die Formulierungstechnik des Mönchs ließen sich im deutschsprachigen Bereich mit Sigehers Marienlob, dem Alemanischen Marienlob, dem Ave Maria in Boppes Hofton und dem Ostmitteldeutschen Marienlob ausmachen, die am Rand oder außerhalb der Gattungstradition Sangspruchdichtung stehen (vgl. Gert Hübner, Lobblumen. Studien zur Genese und Funktion der „Geblümten Rede“ [Bibliotheca Germanica 41], Tübingen-Basel 2000, 160-218). Für den Mönch dürften die lateinischen Vorbilder das Naheliegendere gewesen sein.

42 Ähnlich die Einschätzung Wachingers, Der Mönch von Salzburg (wie Anm. 1), 137. Zum Begriff und der Problematik seiner Anwendung auf mittelalterliche Texte vgl. Bernhard Asmuth, Art. „Perspicuitas“, in: Gert Ueding (Hg.), Historisches Wörterbuch der Rhetorik, Bd. 6, Tübingen 2003, 814-874, 838-842. Zur dichterischen rhetorischen Praxis in mittelalterlichen deutschen Texten: Gert Hübner, „Rhetorische und stilistische Praxis des deutschen Mittelalters“, in: Ulla Fix/Andreas Gardt/Joachim Knape (Hgg.), Rhetorik und Stilistik. Ein internationales Handbuch historischer und systematischer Forschung, 1. Halbband (Handbücher zur Sprach- und Kommunikationswissenschaft 31,1), Berlin-New York 2008, 348-369, 353 zu claritas und obscuritas.

43 Die Melodien der Lieder scheinen mir eher für einen Vortrag durch eine kleinere Sängergruppe oder einen Einzelsänger zu sprechen, weniger für gemeinschaftlichen Gesang einer größeren Gruppe. Fallweise ist der Gesamtambitus recht groß (Tredezime: G 1, G 48; Undezime: G 23, G 33, G 37), einige Lieder haben größere Melismen (G 11, G 36, G 12), zu deren Ausführung es vermutlich einer gewissen Übung bedurfte. 
bereit. Man könnte hier an die Nicht-Kleriker im weiteren Kreis des Hofes, insbesondere an die Frauen am Hof denken. ${ }^{44}$ Da die Texte dabei in ihrer Rhetorik nicht an das Register höfischer Wissensvermittlung der Sangspruchdichtung anknüpfen und die Texte mit ihrer auf Lobpreis ausgerichteten Faktur und mit ihrer häufigen Apostrophe der göttlichen Personen oder Mariens durchaus einen frommen, betenden Rezipienten im Blick haben ${ }^{45}$, könnte man für eine versuchsweise weitere Spezifizierung des Gebrauchs in Salzburg eine Art höfische Frömmigkeitspraxis in Erwägung ziehen, die beispielsweise an Feiertagen im Anschluss an die Gottesdienste im weiteren Kreis des Hofes vollzogen wurde. Auch dies schließt eine Repräsentationsfunktion nicht aus, denn eine solche Praxis mit den dazugehörigen Liedern hätte beispielsweise auf anwesende Gesandte einigen Eindruck machen können. Solches muss allerdings vorerst Vermutung bleiben und ließe sich nur durch neue Quellenfunde zum Salzburger Hof absichern. Tragfähiger wird der Grund für Überlegungen zum Gebrauch, wenn man sich auf die Überlieferung stützen kann.

\section{Mönch-Lieder in Handschriften ZWischen i 400 Und I 450}

Wie und wo nun wurde diese elaborierte, aber zugleich elegante und sinntransparente höfische Liedkunst in den Jahrzehnten nach ihrer Entstehung rezipiert? Derzeit sind

44 SChneider, Hovezuht (wie Anm. 29), 83-89, rechnet aufgrund seiner Lektüre der weltlichen Lieder des Mönchs und in Analogie zum Papsthof in Avignon - wo Pilgrim in den 1360er Jahren Kirchenrecht studiert hatte und für den unter Johannes XXII. (1316-1334) solches bezeugt ist - mit der Anwesenheit von Frauen am Salzburger Hof.

45 Seit Josef Schabasser, Der Mönch von Salzburg in seinen geistlichen Liedern. (Nach der MondseeWiener-Liederhandschrift und sämtlichen Handschriften seiner geistlichen Lieder), phil. Diss. (masch.) Univ. Wien 1936, 26 und 48 f., wurde immer wieder darauf hingewiesen, dass sich die Lieder über das Kirchenjahr hinweg einzelnen Festen zuordnen lassen (vgl. Spechtler, Die geistlichen Lieder [wie Anm. 2], 6 und 29 f.). Die Korpushandschriften verweisen in Überschriften zum Teil auf die zugehörigen Feste. Man hat daher immer wieder einen, liturgischen' oder , paraliturgischen' Gebrauch angenommen, ihn aber relativiert oder in Frage gestellt, je nachdem wie sehr man die - allerdings auf einer problematischen Liturgiedefinition beruhende - Auffassung, vor „der Reformation findet sich kein volkssprachliches Lied in liturgischer Funktion“ (Johannes Janota, Studien zu Funktion und Typus des deutschen geistlichen Liedes im Mittelalter [Münchener Texte und Untersuchungen zur deutschen Literatur des Mittelalters 23], München 1968, 272, zur Liturgiedefinition 25-32) als definitiv gültig betrachtet. Kritisch dazu: Philipp Harnoncourt, Gesamtkirchliche und teilkirchliche Liturgie. Studien zum liturgischen Heiligenkalender und zum Gesang im Gottesdienst unter besonderer Berücksichtigung des deutschen Sprachgebietes, Freiburg im Breisgau 1974; vgl. auch die Rezension von Waldtraut-Ingeborg Sauer-Geppert, in: Beiträge zur Geschichte der deutschen Sprache und Literatur 92 (1971), 264-271. 
63 Handschriften aus diesem Zeitraum bekannt, die geistliche Lieder des MönchKorpus überliefern, in zehn Fällen sind Melodien dazu aufgezeichnet. ${ }^{46}$ Auch wenn mit Überlieferungsverlusten zu rechnen ist, lassen sich doch wegen der großen Anzahl an Textzeugen einige tragfähige Aussagen machen. Mustert man die Überlieferung auf die Typen des Korpus hin durch, zeigt sich, dass die im Korpus auszumachende Trennungslinie zwischen weltlichen und geistlichen Liedern ${ }^{47}$ sich auch dort abzeichnet. In nur fünf Handschriften sind geistliche Lieder gemeinsam mit weltlichen Liedern aus dem Mönch-Korpus überliefert. ${ }^{48}$ Auch die Trennung in Übersetzungen und Eigendichtungen, die sich bei den geistlichen Liedern vornehmen lässt, zeichnet sich tendenziell in der Streuüberlieferung ab. In den dreizehn Fällen, in denen mehr als ein geistliches Lied in einer Handschrift steht, finden sich fünfmal Übersetzungen

46 Die folgenden Ausführungen zur Überlieferung stützen sich auf meine Zusammenstellung der gesamten bekannten Überlieferung der geistlichen Lieder. Für die Ermittlung von Inhalt und Typus der Handschriften sind die Editionen von März, Die weltlichen Lieder (wie Anm. 2), Spechtrer, Die geistlichen Lieder (wie Anm. 2) und Wachinger, Der Mönch von Salzburg (wie Anm. 1) sowie die Angaben im Handschriftencensus (wie Anm. 7) herangezogen worden, ohne dass diese im Folgenden jeweils zitiert würden, weiterhin Kataloge und Spezialliteratur, die fallweise bei Nennung einzelner Codices nachgewiesen werden, wo sie für meine Beurteilung relevante Informationen enthalten. Berücksichtigt wurden Handschriften, bei denen in der Forschungsliteratur eine Datierung in die erste Hälfte des 15. Jahrhunderts angenommen wird, die Obergrenze bildeten Datierungen ,um die Mitte des 15. Jahrhunderts'.

Melodien zu Übersetzungen enthalten: A-MB Man. cart. 82: G 43 (Beatrix Koll, Katalog der Handschriften des Benediktinerstiftes Michaelbeuern bis 1600, Katalogband [Veröffentlichungen der Kommission für Schrift- und Buchwesen des Mittelalters II,6 = Denkschriften der philosophischhistorischen Klasse der Österreichischen Akademie der Wissenschaften 278], Wien 2000, 317-326); A-Wn 4494: G 21; PL-GD 2015: G 13. Melodien zu Eigendichtungen enthalten: Mönch-Hs. L (D-B Mus. ms. 40613): G 42; Mönch-Hs. Sb (F-Sm M 222 C 22, verbrannt): G 42 (Lorenz Welker, Musik am Oberrhein im späten Mittelalter. Die Handschrift Strasbourg, olim Bibliothèque de la Ville, C.22, Habilitationsschrift Univ. Basel 1993); A-Gu 347: G 42; A-Wn Ser. n. 3344 (Liebhard Eghenvelders Liederbuch): G 46 als Teil von Maria ward ein pot gesandt; CH-SGs 392: G 42; D-KA Donaueschingen 111: G 42; D-LEu 1305: G 22.

47 Vgl. März, Die weltlichen Lieder (wie Anm. 2), 5 f.

48 In der Mönch-Hs. St/d (Sterzinger Miszellaneen-Handschrift, Sterzing/Vipiteno, Stadtarchiv, ohne Signatur) sind fünf weltliche (z.T. mit Melodie) und vier geistliche Lieder (ohne Melodie) des Mönchs aufgezeichnet. Hier scheint es ein Interesse am Autor zu geben, der „Mönch“ genannt ist. Zwei Handschriften überliefern den Tischsegen G 42 und weltliche Mönch-Lieder: D-B Mus. ms. 40613 (Lochamer-Liederbuch) und die verbrannte Handschrift F-Sm M 222 C 22 (vgl. Anm. 46). In beiden dominiert das Interesse an der Musik. Die Aufzeichnung in Mönch-Hs. Em (D-Mbs Clm 14256) lässt sich schwer hinsichtlich des Überlieferungskontextes beurteilen, weil es sich bei den Liedern um Nachträge auf einem ursprünglich leeren Blatt am Beginn eines Faszikels handelt (INGeborg Neske, Katalog der lateinischen Handschriften der Bayerischen Staatsbibliothek München. Die Handschriften aus St. Emmeram in Regensburg, Bd. 2: Clm 14131-14260 [Catalogus codicum manu scriptorum Bibliothecae Monacensis IV,2,2], Wiesbaden 2005, 286-291). 
und Eigendichtungen kombiniert, wobei es deutsche sub-melodia-Sequenzen sind, die mit Übersetzungen, denen sie formal näher stehen als die stolligen Strophenlieder, gemeinsam in einem Codex stehen. ${ }^{49}$ In dieser Zusammenstellung nach Liedgattungen des Korpus zeichnet sich schon ab, was markanter hervortritt, wenn man nach den Texten fragt, mit denen Mönch-Lieder gemeinsam überliefert sind. Es lassen sich hier klar umrissene Typen von Überlieferungsgemeinschaften ausmachen:

Lieder des Mönchs stehen in Büchern, bei denen man von einem katechetischen Verwendungszweck ausgehen kann. In solchen Handschriften finden sich Übersetzungen, sub-melodia-Dichtungen und stollige Strophenlieder. Diese Gruppe lässt sich - wenn auch nicht immer ganz trennscharf - in zwei Untergruppen gliedern. Zum einen handelt es sich um Bücher für den Gebrauch von Klerikern ( 13 Codices): Zwischen Predigten und theologischen Traktaten, großteils in Latein, sind in diesen Fällen über den Codex verstreut einige lateinische und deutsche Lieder aufgezeichnet. ${ }^{50}$ Man kann annehmen, dass die Bücher den Klerikern zur Vorbereitung und zum Nachschlagen dienten und dass die Lieder im weltlichen Bereich bei der Unterweisung von Laien, im klösterlichen von Mitbrüdern und Schwestern eingesetzt wurden. Zudem wurden Lieder des Mönchs in geistliche Handschriften aufgenommen, die vom Inhalt eher der Einzellektüre, persönlicher Erbauung

49 Mönch-Hs. M (A-Wn 3946): G 8, G 18, G 28; Mönch-Hs. P (D-Mbs Cgm 444): G 1, G 39; MönchHs. U (D-B mgo 137 + D-Mbs Cgm 5249/64; discissus): G 1, G 5, G 41 (Karin Schneider, Die deutschen Handschriften der Bayerischen Staatsbibliothek München. Die mittelalterlichen Fragmente Cgm 5249-5250 [Catalogus codicum manu scriptorum Bibliothecae Monacensis V,8], Wiesbaden 2005, 115-166); Mönch-Hs. b (A-M 808): G 40, G 41, G 3; Mönch-Hs. c (I-UD 58): G 13, G 18, G 43 (zur Datierung: Maria Amalia d’Aronco, „Il Mittit ad virginem del Monaco di Salisburgo del ms. n. 58 dell'Archivio Capitolare di Udine“, in: Annali. Istituto Universitario Orientale. Filologia Germanica 23 [1980], 23-35, 25-27).

50 Mönch-Hs. Em (D-Mbs Clm 14256); Mönch-Hs. N (A-KN 533; Online-Katalog manuscripta.at: Mittelalterliche Handschriften in Österreich <http://manuscripta.at/?D=709>, 12.09.2014); MönchHs. Q (D-Mbs Clm 5879); Mönch-Hs. g (D-Mbs Clm 27423; Hermann Hauke, Katalog der lateinischen Handschriften der Bayerischen Staatsbibliothek München: Clm 27270-27499, Wiesbaden 1975, 211-213); A-Gu 347; A-Gu 951; A-Gu 271 (vgl. Franz Viktor Spechtler, Der Mönch von Salzburg. Untersuchungen über Handschriften, Geschichte, Gestalt und Werk des Dichters und Komponisten als Grundlegung einer textkritischen Ausgabe, phil. Diss. (masch.) Univ. Innsbruck 1963, 59); A-MB Man. cart. 82 (Koll, Katalog [wie Anm. 46], 317-326); A-SF XI 37 (Albin Czerny, Die Handschriften der Stiftsbibliothek St. Florian, Linz 1871, 12 f.); A-Wn 3584 (Tabulae codicum manu scriptorum praeter graecos et orientales in Bibliotheca Palatina Vindobonensi asservatorum, Bd. 3, Wien 1869, 26); A-Wn 14863 (Dass., Bd. 8, Wien 1893, 99 f.); D-Mbs Clm 7742 (Karl Halm, Catalogus codicum latinorum Bibliothecae Regiae Monacensis, Bd. I,3: Codices num. 5251-8100 complectens [Catalogus codicum manu scriptorum Bibliothecae Regiae Monacensis III,3], München 1873 [Nachdruck Wiesbaden 1968], 193); PL-GD 2015 (Отто GüNTHeR, Katalog der Handschriften der Danziger Stadtbibliothek, Bd. 3, Danzig 1909, 146-149). 
und dem Gebet dienten; in ihnen sind die Texte zumeist überwiegend deutsch (I 8 Codices). ${ }^{51}$ Ein Teil von ihnen wurde in Klöstern geschrieben und entstammt der Frömmigkeitspraxis von Nonnen und Laienbrüdern, bei anderen lässt sich nicht immer spezifizieren, ob sie in klösterliche oder laikale Gebrauchszusammenhänge gehören.

In neun Handschriften sind Lieder des Mönchs innerhalb von umfangreichen oder kleinen Sammlungen meisterlicher Lieder aufgezeichnet. In sieben Fällen stehen diese Meisterliedersammlungen ebenfalls in katechetischen Handschriften, darin aber stets als Block und nicht über den Codex verteilt. ${ }^{52}$ In zwei Fällen handelt es sich um ,Meisterliederhandschriften', die fast ausschließlich diesem Liedtyp gewidmet sind. ${ }^{53}$

51 Mönch-Hs. U (D-B mgo 137 + D-Mbs Cgm 5249/64; discissus); Mönch-Hs. b (A-M 808); A-Wn 4494 (März, Die weltlichen Lieder [wie Anm. 2], 105 f.; Gisela Kornrumpf, „In dulci jubilo. Neue Aspekte der Überlieferungsgeschichte beider Fassungen des Weihnachtsliedes“, in: Johannes SpICKER u. a. [Hg.], Edition und Interpretation. Neue Forschungsparadigmen zur mittelhochdeutschen Lyrik. Festschrift Helmut Tervooren, Stuttgart 2000, 159-190, 182); CH-Bu B XI 19 (Gustav Meyer/Max Burcknardt, Die mittelalterlichen Handschriften der Universitätsbibliothek Basel. Beschreibendes Verzeichnis, Abteilung B: Theologische Pergamenthandschriften, Bd. 2: Signaturen B VIII 11-B XI 26, Basel 1966, 1028-1045); D-As $2^{\circ}$ Cod. 438 (Wolf Genrt, Die Handschriften der Staats- und Stadtbibliothek Augsburg, $2^{\circ}$ Cod 401-575 [Handschriftenkataloge der Staats- und Stadtbibliothek Augsburg V], Wiesbaden 1993, 52-59); D-B mgf 742; D-Dl Mscr. M 60; D-DÜl F 55; D-KA Lichtenthal 77; D-Mbs Cgm 353 (Schneider, Cgm 351-500 [wie Anm. 10], 28-33); D-Mbs Cgm 834 (Karin Schneider, Die deutschen Handschriften der Bayerischen Staatsbibliothek München. Cgm 691-867 [Catalogus codicum manu scriptorum Bibliothecae Monacensis V,5], Wiesbaden 1984, 536-538); D-Mbs Cgm 5241 (Karin Schneider, Die deutschen Handschriften der Bayerischen Staatsbibliothek München. Die mittelalterlichen Handschriften aus Cgm 4001-5247 [Catalogus codicum manu scriptorum Bibliothecae Monacensis V,7], Wiesbaden 1996, 567-573); D-Ngm 23212 (Lotte Kurras, Die deutschen mittelalterlichen Handschriften: Teil 1. Die literarischen und religiösen Handschriften. Anhang: Die Hardenbergschen Fragmente [Die Handschriften des Germanischen Nationalmuseums Nürnberg 1], Wiesbaden 1974, 92 f.); D-Nst Cent. VI 86 (Karin Schneider, Die Handschriften der Stadtbibliothek Nürnberg, Bd. 1: Die deutschen mittelalterlichen Handschriften [Beschreibung des Buchschmucks: Heinz Zirnbauer], Wiesbaden 1965, 231-239); D-Nst Cent VII 24 (ebda., 296-305); D-Nst Cent. VII 86 (ebda., 328-334); F-Pn allem. 117; SI-Ln 140 (Milкo Kos/Franjo STELÈ, Codices aetatis mediae manu scripti in Slovenia reperiuntur [Srednjeveški rokopisi v Slovenjii/ S sodelovanjem Franja Stelèta], Ljubljana 1931, 107).

52 Mönch-Hs. S (D-Mbs Clm 14574); D-AN lat. 161 (Depositum in D-Mbs); D-KA St. Georgen 74 (Frieder Schanze, Meisterliche Liedkunst zwischen Heinrich von Mügeln und Hans Sachs [Münchener Texte und Untersuchungen zu deutschen Literatur des Mittelalters 83], Bd. II: Verzeichnisse, München 1984, 188 f.); D-Mbs Cgm 268 (Karin SCHneIder, Die deutschen Handschriften der Bayerischen Staatsbibliothek München. Cgm 201-350 [Catalogus codicum manu scriptorum Bibliothecae Monacensis V,2], Wiesbaden 1970, 185-187); D-Mbs Clm 8481; D-Mbs Clm 15133; D-Sl theol et phil. $8^{\circ} 19$ (Schanze, Meisterliche Liedkunst, Bd. II, 236 f.).

53 Es handelt sich um D-Mbs Cgm 351 und D-Mbs Cgm 1019. Der Cgm 1019 (Mitte 15. Jahrhundert) ist ein eigenständiges Bändchen mit 22 Meisterliedern über dessen Entstehung und ursprünglichen 
Einmal ist G I gemeinsam mit Konrads von Würzburg Goldener Schmiede überliefert, ein von seiner sprachartistischen Gestaltung her anspruchsvoller Text, dessen Verfasser von den frühen Meistersingern zu den vorbildlichen alten Dichtern gezählt wurde. ${ }^{54}$ In diesem Gebrauchskontext sind neben G I und den Hymnusübersetzungen $\mathrm{G} 43^{55}$ und $\mathrm{G} 47^{56}$ in der Hauptsache stollige Strophenlieder überliefert. In drei dieser Handschriften wird der Mönch auch als Autor des Tones genannt. ${ }^{57}$ Die Überlieferung legt nahe, dass Mönch-Lieder bereits in der ersten Hälfte des I 5 . Jahrhunderts in den meisterlichen Traditionszusammenhang gerückt wurden. Meisterlieder und Mönch-Lieder bzw. Mönch-Lieder als Meisterlieder wurden offenbar im selben Zeitraum von klerikaler Seite rezipiert und aufgezeichnet.

Zwar lassen sich nicht alle 63 Handschriften der Streuüberlieferung aus der ersten Hälfte des I 5 . Jahrhunderts in diese Überlieferungskontexte einordnen - und im Einzelfall sind weitere Differenzierungen möglich -, aber die Hauptrezeption der geistlichen Lieder des Mönchs in der ersten Hälfte des I 5 . Jahrhunderts dürfte damit erfasst sein: Erbauung und Gebet einerseits, meisterliche Kunstübung andererseits. Inwiefern aber passten die Lieder des Mönchs in diese Gebrauchszusammenhänge?

Gebrauchszusammenhang nichts bekannt ist (SCHNeIder, Cgm 888-4000 [wie Anm. 10], 58-62). Beim zweiten Teil des Com 351 (fol. 174-276) - im ersten, etwas älteren Teil (fol. 1-173) steht der Traktat ,Erkenntnis der Sünde - handelt es sich um die „älteste und umfangreichste der frühen Meisterliederhandschriften und zugleich [um] das erste erhaltene Dokument des Nürnberger Meistergesangs" (Schanze, Meisterliche Liedkunst [wie Anm. 52], Bd. I, 87). Dieser zweite Teil des Codex ist in sich wieder zweiteilig: Die erste Hand zeichnete zuerst eine deutsche Übersetzung der Passionsgeschichte und deutsche Gebete auf, dann auf einer zweiten Lage Meisterlieder. Diese Meisterliedersammlung wurde entweder auf weiteren Lagen fortgesetzt oder aber später mit einer anderen Sammlung verbunden. Das Mönch-Lied G 33 steht in diesem zweiten Teil. Vgl. im Detail Schanze, Meisterliche Liedkunst (wie Anm. 52), Bd. I, 87-94, Bd. II, 135-137 und 208; Schneider, Cgm 351500 (wie Anm. 51), 17-26; Tilo Brandis, Der Harder. Texte und Studien (Quellen und Forschungen zur Sprach- und Kulturgeschichte der germanischen Völker N.F. 13 [137]), Berlin 1964, 89-102; Horst Brunner, Die alten Meister. Studien zu Überlieferung und Rezeption der mittelhochdeutschen Sangspruchdichter im Spätmittelalter und in der frühen Neuzeit (Münchener Texte und Untersuchungen zur deutschen Literatur des Mittelalters 54), München 1975, 139 f. und 163-171.

54 D-Hs scrin. 193; zur Wertschätzung älterer Dichter durch die Meistersinger: Brunner, Die alten Meister (wie Anm. 53), 12-31.

55 D-Mbs Clm 8481 (Schanze, Meisterliche Liedkunst [wie Anm. 52], Bd. II, 214; Gisela KornRumpf, „Mülich von Prag, Pfalz von Straßburg, Albrecht Lesch. Neues zur Überlieferung“, in: Zeitschrift für deutsches Altertum und deutsche Literatur 106 [1977], 121-137, 126).

56 D-Mbs Clm 15133 (Schanze, Meisterliche Liedkunst [wie Anm. 52], Bd. II, 214; Karl Halm, Catalogus codicum latinorum Bibliothecae Regiae Monacensis, Bd. II,3: Codices num. 15121-21313 complectens [Catalogus codicum manu scriptorum Bibliothecae Regiae Monacensis IV,3], München 1878 [Nachdruck Wiesbaden 1969], 2 f.).

57 Siehe Anm. 10. 
Dazu soll abschließend der Blick nochmals auf die Lieder G 3, G io und G 33 gerichtet werden.

G 3 findet sich im von Lienhart Peuger geschriebenen Codex Mellicensis 808 . Peuger, um I 390 geboren, legte I 420 in Melk die Profess ab. In der Professliste wird er als vom Kriegerstand zum Klosterleben Bekehrter genannt. ${ }^{58}$ Er war im reformierten Kloster als Schreiber, Redaktor, Dichter und wahrscheinlich als Übersetzer tätig. Peuger bezeichnete sich selbst als Laien ${ }^{59}$, sein Wirken galt der Seelsorge und Bildung der Melker Laienbrüder. Im Melker Codex 808 stehen zunächst eine Übersetzung des Psalters, die vermutlich von Peuger selbst stammt ${ }^{60}$, dann Übertragungen alt- und neutestamentlicher Cantica. Es folgen die Übersetzungen der Sequenz Lauda Sion salvatorem $^{61}$ und des Hymnus Pange lingua gloriosi (G 40), daran schließt G 3 an. Daran reihen sich vier von Lienhart Peuger verfasste Reimpaarreden, in denen er das klösterliche Leben behandelt und seine Bekehrung wie auch sein Leben als geistlicher Ritter und Marienverehrer darstellt. Insgesamt sind die Reimpaarreden „durchdrungen von einer eher naiv zu nennenden Marienverehrung“, die „stilisierte Autobiographie dient als Exempel moraldidaktischer Unterweisung“. ${ }^{62}$ Die Übersetzungen der liturgischen Texte verhalfen den Melker Laienbrüdern wohl zu einem besseren Verständnis der Liturgie, die Reimpaarreden dagegen zielten eher auf Ermahnung und persönliche Erbauung. G 3 steht im Codex wie eine Art Scharnier: Von der Form der Sequenz her mit den beiden vorangehenden Übersetzungen liturgischer Texte verbunden, fügt es sich von der Marienthematik her gut zu den folgenden Texten. Was die sprachkünstlerische Qualität angeht, heben sich die Mönch-Texte allerdings sehr deutlich von ihrem Umfeld ab. Sie wurden hier wohl nicht als Zeichen künstlerischer Kompetenz geschätzt, sondern dienten wie die übrigen Texte der Unterweisung. Das Schmuckelement der zusätzlichen Mittelreime in Versikel VI ist denn auch durch

58 „Ex armigero conversus“, siehe Freimut Löser, Meister Eckhart in Melk. Studien zum Redaktor Lienhart Peuger (Texte und Textgeschichte 48), Tübingen 1999, 31. Vgl. auch Fritz Peter Knapp, Die Literatur des Spätmittelalters in den Ländern Steiermark, Kärnten, Salzburg und Tirol von 1237 bis 1439, 2. Halbband: Die Literatur zur Zeit der habsburgischen Herzöge von Rudolf IV. bis Albrecht V. (Geschichte der Literatur in Österreich von den Anfängen bis zur Gegenwart 2,2), Graz 2004, 248-260.

59 Löser, Meister Eckhart in Melk (wie Anm. 58), 31.

60 Freimut Löser, Art. „Peuger, Lienhart“, in: ${ }^{2} V L 7$ (1989), 534-537.

61 Diese Übersetzung des Lauda Sion verwendet einzelne Versikel von G 41, siehe Wachinger, Der Mönch von Salzburg (wie Anm. 1), 53, und Spechtler, Die geistlichen Lieder (wie Anm. 2), 323-325. Gisela Kornrumpf (München), hat mich freundlicherweise darauf aufmerksam gemacht (briefliche Mitteilung, 3. Dezember 2011), dass sich dieser Text auch in D-As $2^{\circ}$ Cod 438, fol. $291 \mathrm{r}-\mathrm{v}$ findet (vgl. Wolf Gehrt, Die Handschriften der Staats- und Stadtbibliothek Augsburg $2^{\circ}$ Cod 401-575 [Handschriftenkataloge der Staats- und Stadtbibliothek Augsburg 5], Wiesbaden 1993, 59).

62 Löser, Meister Eckhart in Melk (wie Anm. 58), 42. 
Umstellungen oder Umformulierungen beseitigt worden, das Akrostichon war in diesem Zusammenhang funktionslos geworden. G 3 dürfte von den Melker Laienbrüdern als gemeinschaftliches oder als Einzelgebet benutzt worden sein, ein Amen ist ihm am Ende zugefügt. ${ }^{63}$

G Io findet sich im Rahmen einer größeren, mehrfach überlieferten Kompilation erbaulicher Texte, die in der germanistischen Forschung als ,Oberrheinisches Erbauungsbuch' bezeichnet wird; ein größerer Abschnitt dieser Kompilation trägt in einigen Handschriften den Titel Der slecht weg zuo dem himelrich. ${ }^{64}$ Dem Lied gehen geistlich grundierte, auf die Lebenspraxis ausgerichtete Texte voran (Ehelehre u. ä.). Auf G Io folgen mit Der slecht weg Textabschnitte, die stärker den religiösen Lebensbereich betreffen, etwa die Sündenstrafen, die Zehn Gebote, die Vorbereitung zum Empfang der Kommunion und anderes mehr behandeln. G Io fügt sich gut an dieser Stelle der Kompilation zwischen eher lebenspraktischen Texten - ein Gebet ist auch eine Angelegenheit des täglichen Lebens - und dem ersten der eher theologischen Texte ein, der die Sündenstrafen behandelt. G Io ist nämlich eine Ablasszusage vorangestellt: „Der babest bonifacius hat geben zu diesem noch geschribenen gebete: wer das sprichet mit andaht der hat also manegen tag apeloos also wort an disem gebette geschriben hie noch stont." 65

Das Lied ist auch hier zu einem Gebet geworden, das gesprochen wird, nicht gesungen. Und auch hier kann man mit dem Herausgeber feststellen, dass die „feine strophische Struktur [...] gar nicht zu den ansonsten relativ simpel fortlaufenden Paarreimen der übrigen Texte passen“ will, und G Io sich als einziger Text „inhaltlich kundig auf die Prophetie und die Psalmen"66 bezieht. In der Tat setzt G Io, wie oben dargelegt, einiges an Wissen voraus, wenn man den Text in seinem gan-

63 Bei den Übersetzungen steht in A-M 808 als Überschrift der Beginn der lateinischen Vorlage, bei G 3 ist ebenfalls der Beginn hier der Formvorlage Salve, mater salvatoris als Überschrift verwendet (vgl. Spechtler, Die geistlichen Lieder [wie Anm. 2], 71-73, 129, 313 und 317). Sollte Peuger es als Übersetzung aufgefasst haben?

64 Arnold Otto/Burghart Wachinger, Art. „,Der slecht weg' und das ,Oberrheinische Erbauungsbuch“", in: ${ }^{2} V L 11$ (2004), 1437-1441. Die Kompilation ist in fünf Handschriften überliefert, vier davon aus der ersten Hälfte des 15. Jahrhunderts: D-B mgf 742; D-Dl Mscr. M 60; D-DÜl F 55; D-KA Lichtenthal 77. Ausgabe: „der slecht weg zuo dem hinmelrich“. Ein oberrheinisches Erbaunngsbuch. Edition und Kommentar: ARnold Otтo (Texte des späten Mittelalters und der frühen Neuzeit 42), Berlin 2005.

65 Отто, Ein oberrheinisches Erbauungsbuch (wie Anm. 64), 86. Zu einem ebenfalls wegen einer Ablasszusage breit überlieferten Lied vgl. Birigt Lodes, „,Maria zart' und die Angst vor Fegefeuer und Malafrantzos - Die Karriere eines Liedes zu Beginn des 16. Jahrhunderts“, in: Trossinger Jahrbuch für Renaissancemusik 1 (2001), 99-131, dort 116 (Anm. 30) und 118 f. (Anm. 36) weitere Literatur zum Ablass.

66 Отто, Ein oberrheinisches Erbaunngsbuch (wie Anm. 64), 85. 
zen Bedeutungsspektrum erfassen will. Aber diese Bezüge dienten vermutlich schon produktionsseitig nicht dezidiert der Wissensvermittlung, sondern waren für Kenner bestimmt, und ein Text wie G Io war auch für einen weniger kundigen Beter kaum problematisch, denn die zentralen Botschaften - Maria wird gelobt und gepriesen; alles in der Schrift weist auf das zentrale Heilsereignis der Menschwerdung Christi und damit auf Maria hin - werden aus dem Text auch dann klar, wenn man nur über christliches Grundwissen verfügt und nicht jedes biblische Detail kennt.

Die Schreiber haben in allen vier Handschriften der Kompilation die Strophenform teilweise entstellt: Verse fehlen teilweise oder vollständig ${ }^{67}$, der Reim ist an einigen Stellen gestört, es finden sich vereinfachende Lesarten. Beispielhaft kann man die Tendenz zur Simplifikation an G I0, I, I 5-I 8 zeigen: Hier ist V. I 7 ,und singet got der eren krei“ ([ihr himmlischen Heerscharen] singt Gott den Ruf der Ehre) im Erbauungsbuch in „und singen lop der eren kron“ umgewandelt, vermutlich weil das Wort „krei“ (bairische Form für mhd. krîe) unverständlich war. In zwei Handschriften ist danach V. I 8 ausgefallen, so dass ein Reimwort fehlt, in den anderen Handschriften reimen V. I7 und I 8 miteinander, statt V. 17 mit I 6 und V. I 8 mit 22 und $26 .{ }^{68}$ Trotz solcher Änderungen bleibt der Text insgesamt in diesen Handschriften gut verständlich.

Der Verwendung als Gebet kamen die anspruchsvollen Texte der Mönch-Lieder entgegen, weil sie sich schon produktionsseitig am Stilprinzip der claritas orientierten. Auch für Rezipienten, die an der rhetorisch-poetischen Gestalt vollkommen desinteressiert waren, trat ihre Funktion des Lobens und Um-Beistand-Bittens klar hervor. Zudem mochten sie von Fall zu Fall - etwa unter den Laienbrüdern im Kloster - auch die Möglichkeit bieten, sich vertieft mit Glaubenswahrheiten zu befassen, weil beispielsweise in Gestalt topischen Marienlobs viele Bezüge auf das Alte Testament eingebunden waren, die man, wenn man wollte, alle entschlüsseln oder sich erklären lassen konnte.

Dagegen ist G 33 in die frühe und vergleichsweise umfangreiche Sammlung von Meisterliedern des Cgm 35 I aufgenommen. ${ }^{69}$ Für die Meisterliedersammler und -dichter waren die Mönch-Lieder nun gerade wegen ihrer Faktur interessant. MönchLieder und Meisterlieder entsprechen sich in ihrer Form: Die Strophen sind stollig

67 Vgl. die Fassung nach D-KA Lichtenthal 77 und die Lesarten bei Отто, Ein oberrheinisches Erbauungsbuch (wie Anm. 64), 254-260 mit der Fassung bei SPECHTLER, Die geistlichen Lieder (wie Anm. 2), zur Textkritik Wachinger, Der Mönch von Salzburg (wie Anm. 1), $19 \mathrm{f}$.

68 Ich gebe zur Veranschaulichung das Reimschema der Strophe (die das Schema störende Abweichung in der Fassung des Erbauungsbuches ist fett hervorgehoben, , | 'steht für Grenze zwischen den beiden Stollen, , || 'trennt Stollen und Abgesang). ,Korrektes' Schema: aaaaaab | ccccccb || ddde ddde ddde; im Erbauungsbuch vereinfacht zu: aaaaaab | ccccccb || dde dddf dddf oder || ddee dddf dddf.

69 D-Mbs Cgm 351, fol. 227r-228v. Vgl. Schneider, Cgm 351-500 (wie Anm. 51), 17-26 und Schanze, Meisterliche Liedkunst (wie Anm. 52), Bd. I: Untersuchungen, 87-94, Bd. II: Verzeichnisse, 83-88. 
gebaut und umfangreich, die Reimschemata sind anspruchsvoll. Auch die rhetorische und sprachkünstlerische Brillanz der Mönch-Texte dürfte dazu beigetragen haben, sie in die Meister-Überlieferung einzugliedern; in der späteren Meisterliedersammlung der Kolmarer Liederhandschrift sind selbst unstollige Lieder wie G I, G 45 und W I aufgenommen. ${ }^{70}$ Die Sammlung von Liedern im Cgm 35 I ist zudem insgesamt stark auf Geistliches ausgerichtet, so dass sich G 33 auch thematisch gut einfügt. Und neben den formalen Gemeinsamkeiten lassen sich gewisse Ähnlichkeiten in der inhaltlichen Progression der Lieder ausmachen. So kann man etwa in der, Tagweise‘ Albrecht Leschs $^{71}$, in zwei Liedern in der ,Schlüsselweise 'Fritz Ketners ${ }^{72}$ und in einem Lied in Frauenlobs ,Zartem Ton ${ }^{73}$ im Textverlauf einen Durchgang durch die heilsgeschichtlichen Ereignisse beobachten, ähnlich wie in G Io und G 33. Das dreistrophige Lied Globt seystu Kunic sabaot in Ketners ,Schlüsselweise، verwendet wie G 33 mehrfach die Versanapher. Auch in diesen Liedern steht am Ende die Bitte um Beistand und Fürsprache. Allerdings gibt es auch Unterschiede in der Faktur: Die ,Tagweise‘ Leschs und Ketners ,Schlüsselweise‘ zeigen deutlich stärker als die Mönch-Lieder einen explikativen Duktus und sie entfalten die heilsgeschichtlichen Ereignisse breit in narrativer Weise.

\section{Zusammenfassung und Ausblick}

Die wesentlichen Gebrauchszusammenhänge, in denen Mönch-Lieder auftreten, sind seelsorgerisch-erbaulicher Art einerseits, die meisterliche Liedkunst andererseits. Im ersten Fall sind aus den gesungenen Liedern großteils gesprochene Gebete geworden, im zweiten Fall kann man von Gesangsvortrag ausgehen, weil die Handschriften in Überschriften die Töne angeben. Beim seelsorgerisch-erbaulichen Kontext war für die Verwendung der Mönch-Lieder wohl primär der Inhalt und die Verständlichkeit

70 Vgl. Michael Baldzuhn, Vom Sangspruch zum Meisterlied. Untersuchungen zu einem literarischen Traditionszusammenhang auf der Grundlage der Kolmarer Liederhandschrift (Münchener Texte und Untersuchungen zur deutschen Literatur des Mittelalters 120), Tübingen 2002, zu den Mönch-Liedern 370-376.

71 D-Mbs Cgm 351, fol. 219r-220v; Edition: Die kleineren Liederdichter des 14. und 15. Jahrhunderts, hg. von Thomas Cramer, Bd. 2, München 1979, 208-225.

72 D-Mbs Cgm 351, fol. 220v-223v. Edition: Cramer, Die kleineren Liederdichter (wie Anm. 71), 123131 und 503-506.

73 D-Mbs Cgm 351, fol. 224v-225r. Edition: Sangsprüche in Tönen Frauenlobs. Supplement zur Göttinger Frauenlob-Ausgabe, hg. von Jens Haustein/KarL Stackmann (Abhandlungen der Akademie der Wissenschaften in Göttingen, Philologisch-historische Klasse, Dritte Folge 232), Göttingen 2000, Bd. 1, 188 f. (VIII,204). 
entscheidend. Für die frühen städtischen Meistersinger wird zwar auch der Inhalt eine Rolle gespielt haben, aber im Vordergrund stand die Sprachkunst der Mönch-Texte. Neben der metrisch-musikalischen Form der Stollenstrophe wird auch ihre rhetorische Durchgestaltung die Mönch-Lieder attraktiv gemacht haben; G 33 ist ja durch Anaphern in dieser Hinsicht besonders ausgezeichnet.

Vielleicht sollte man die Gebrauchssphären aber auch nicht als ganz scharf geschiedene betrachten. Zwar sind meisterliche Liedkunst - über deren Gebrauch insgesamt wenig bekannt ist - , der vorreformatorische Meistergesang und Frömmigkeitsübung innerhalb und außerhalb des Klosters grundsätzlich verschiedene Gebrauchszusammenhänge. Aber Texte konnten zwischen den Gebrauchssphären zirkulieren, wie die Überlieferung von Meisterliedern in seelsorgerisch-erbaulichen Handschriften zeigt. Und betrachtet man die Personengruppen, die die Texte gebrauchen, kann man feststellen, dass es in beiden Fällen (auch) Laien sind, die ein deutliches Interesse an geistlichen Inhalten haben. ${ }^{74}$

In beiden Fällen aber finden sich Lieder bereits zwanzig bis dreißig Jahre nach ihrer Entstehung in einem Gebrauchszusammenhang, bei dem der Rahmen höfischer Repräsentation, den man sich für Produktion und primäre Rezeption am Ende des I 4. Jahrhunderts in Salzburg vorstellen kann (siehe oben), keinerlei Rolle mehr spielt. Demonstration von poetischer Kennerschaft und Gelehrtheit nach außen und damit verbunden ein bestimmtes $\mathrm{Ma}$ an Selbstvergewisserung dürften im Bereich der Frömmigkeitsübung keine, im frühen städtischen Meistergesang eine marginale Rolle gespielt haben. Ein Führungsanspruch wurde in keinem Fall damit begründet. Die Gebrauchszusammenhänge der ersten Hälfte des I 5 . Jahrhunderts aktualisieren freilich nur eine der möglichen Rezeptionshaltungen, die in den Texten angelegt waren.

Im Vergleich mit der Streuüberlieferung gewinnt auch die Überlieferung der Korpushandschriften weiter an Profil. Ihr Bestreben, alle Typen des Mönch-CEuvre festzuhalten, ihr Wunsch, den Autor zu identifizieren, sowie die Hinweise auf Salzburg

74 Dass Bücher und Texte zwischen städtischen laikalen und weltgeistlichen Personengruppen und einem Kloster zirkulieren konnten, hat Johanna Thali für das Frauenkloster St. Andreas in Engelberg und Luzern dargestellt („Regionalität als Paradigma literarhistorischer Forschung zur Vormoderne. Das Beispiel des Benediktinerinnenklosters St. Andreas in Engelberg", in: Barbara Fleith/René WeTZEL [Hgg.], Kulturtopographie des deutschsprachigen Südwestens im späteren Mittelalter. Studien und Texte [Kulturtopographie des alemannischen Raumes 1], Berlin-New York 2009, 229-262, 252-258); vgl. auch Karin SCHNEIder („Die Bibliothek des Katharinenklosters in Nürnberg und die städtische Gesellschaft", in: Bernd Moeller/Hans Patzke [Hgg.], Studien zum städtischen Bildungswesen des späten Mittelalters und der frühen Neuzeit [Abhandlungen der Akademie der Wissenschaften in Göttingen, Philologisch-historische Klasse, 3. Folge 137], Göttingen 1983, 70-82) für das Dominikanerinnenkloster St. Katharina in Nürnberg. Allerdings ist anzumerken, dass in beiden Fällen nur der Weg von der Stadt ins Kloster, nicht umgekehrt, klar belegt ist. 
und Erzbischof Pilgrim verleihen ihnen einen deutlich retrospektiven Zug: Hier wurde in der zweiten Hälfte des I 5. Jahrhunderts etwas aufgezeichnet, das in seiner ursprünglichen Existenzweise vermutlich schon nicht mehr vorhanden war.

Dieser Befund wirft nun einige weitere Fragen auf, die ich abschließend skizzieren möchte. Die Beobachtung, dass Lieder des Mönch-Korpus offenbar schon früh in den Gattungszusammenhang der Meister-Tradition eingereiht wurden, dort aber doch „am Rande“75 stehen, gibt, was die Produktionsseite angeht, noch einmal zu bedenken, ob der Mönch und sein Umkreis nicht selbst bereits auf diesen Traditionsstrang zurückgegriffen haben könnten. ${ }^{76}$ Auf der Rezeptionsseite wäre zu überlegen, was neben der genannten rhetorischen Durchgestaltung und der Übereinstimmung im formalen Groß-Typus ,Lied in stolligen Strophen' für die frühen Meistersinger ein Grund gewesen sein könnte, Mönch-Lieder zu tradieren. Eine mögliche Antwort ließe sich aus der Formengeschichte des deutschsprachigen Liedes ableiten: Der Groß-Typus ,stollige Strophe 'ist in der Sangspruchdichtung des I3. Jahrhunderts und in der meisterlichen Liedkunst durchaus weiter differenziert. Johannes Rettelbach hat die Bauformen der Töne in der Jenaer Liederhandschrift, die wegen der fast nur in ihr überlieferten Melodien unser Bild von den Formen der Sangspruchdichtung stark prägt, mit denen der Kolmarer Liederhandschrift verglichen. Dabei zeigt sich, dass die Präferenz der Jenaer Liederhandschrift für Formen mit drittem Stollen (AABA und Variationen davon) sich in der jüngeren Handschrift nicht fortsetzt. ${ }^{77}$ Man könnte also danach fragen, wie sich die Töne der neun stolligen Lieder im Mönch-Korpus zu den älteren bzw. jüngeren Tönen verhalten.

Sowohl bei der Frage nach den produktionsseitigen Gattungszusammenhängen als auch jener nach der rezeptionsseitigen Einordnung in Gattungstraditionen sollten die Melodien einbezogen werden. Ansätze zu einer Beschreibung des Melodiestils deutschsprachiger Lieder gibt es durchaus, allerdings zielen diese meist nur auf einzelne Euvres. ${ }^{78}$ Hilfreich für die Frage nach dem Melodiestil kann die Berücksichti-

75 Baldzuhn, Vom Sangspruch zum Meisterlied (wie Anm. 69), 370.

76 Wachinger, Der Mönch von Salzburg (wie Anm. 1), 128-130, hat den neun Liedern in stolligen Strophen ihre Bezeichnung ,meisterlich“ ausdrücklich „von der Seite der Rezeption her“ (128) verliehen und auf Überlegungen Gisela Kornrumpfs hin die geistliche Kontrafakturpraxis als Traditionszusammenhang ins Spiel gebracht.

77 Johannes Rettelbach, „Die Bauformen der Töne in der ,Jenaer ${ }^{\star}$ und der ,Kolmarer Liederhandschrift‘ im Vergleich“, in: Jens Haustein/Franz Körndle (Hgg.), Die, Jenaer Liederhandschrift. Codex-Geschichte - Umfeld, Berlin-New York 2010, 81-97.

78 Walter Salmen, „Zur Melodik des späthöfisch-bürgerlichen Minnesangs“, in: Rheinisch-Westfälische Zeitschrift für Volkskunde 1 (1954), 103-112; Ewald JaMmERs, „Hugo von Montfort, ein letzter Minnesänger (Zu seinem 600jährigen Geburtstage)“, in: Jahrbuch des Vorarlberger Landesmuseumsvereins 1 (1957), 34-45; Ders., „Anmerkungen zur Musik Wizlaws von Rügen“, in: Kurt Dorfmüller 
gung der einstimmigen lateinischen Liedkunst sein. Im I 4. und I 5 . Jahrhundert sind eine Reihe lateinischer Lieder in stolliger Strophenform überliefert, deren Texte der Forschung im ersten Band der Analecta hymnica unter den Cantiones bohemicae bekannt gemacht wurden. ${ }^{79}$ Teilweise gibt es Übereinstimmung im metrischen Schema und im Reimschema mit deutschen Liedern. ${ }^{80} \mathrm{Zu}$ ihnen sind großteils Melodien

(Hg.), Quellenstudien zur Musik. Wolfgang Schmieder zum 70. Geburtstag, Frankfurt am Main etc. 1972; Lukas Richter, „Probleme des spätmittelalterlichen deutschen Lieds“, in: Deutsche Literatur des Spätmittelalters. Ergebnisse, Probleme und Perspektiven der Forschung (Wissenschaftliche Beiträge der Ernst-Moritz-Arndt-Universität Greifswald. Deutsche Literatur des Mittelalters 3), Greifswald 1986, 142-165; Lorenz Welker, „Die Melodien des Burkhard Mangolt“, in: Hugo von Montfort. Einführung zum Faksimile des Cpg 329 der Universitätsbibliothek Heidelberg (Facsimilia Heidelbergensia 5), Wiesbaden 1988, 47-60; Franz Viktor Spechtler/Hans Waechter, „Psalmodie und Sangverslyrik. Zu den Melodien des Bruder Wernher", in: Horst Brunner (Hg.), Neue Forschungen zur mittelhochdeutschen Sangspruchdichtung = Zeitschrift für deutsche Philologie, Sonderheft 119 (2000), 50-58; Mark Emmanuel Amtstätter, „Ihc wil singhen in der nuwen wise eyn let. Die Sup-Strophik Wizlavs von Rügen und die Einheit von Wort und Ton im Minnesang“, in: Beiträge zur Geschichte der deutschen Sprache und Literatur 124 (2002), 466-483; Agnes Grond, „Einführung zu den Melodien der Handschrift cpg 329“, in: Hugo von Montfort. Das poetische Werk. Mit einem Melodie-Anhang, hg. von Wernfried Hofmeister, Berlin-New York 2005, 211-217; Florian Kragl, „Walther, Neidhart und die Musik. Möglichkeiten der musikalischen Analyse“, in: Thomas Bern (Hg.), Der mittelalterliche und der neuzeitliche Walther. Beiträge zu Motivik, Poetik Überlieferungsgeschichte und Rezeption (Walther-Studien 5), Frankfurt am Main 2007, 165-212.

79 Analecta hymnica medii aevi, Bd. 1: Cantiones Bohemicae: Leiche, Lieder und Rufe des 13., 14. und 15. Jahrhunderts, hg. von Guido Maria Dreves, Leipzig 1886. Dreves nannte die Lieder in stolligen Strophen „Leich“ (ebda., 9-11; vgl. Gisela KornrumpF, „Quid admiramini, quid opinamini, filie Jherusalem de partu novitatis. Eine Weihnachts-Cantio in Böhmen und anderswo“, in: Dominique Fliegler/VÁclav Boк [Hgg.], Deutsche Literatur des Mittelalters in und über Böhmen. Vorträge der internationalen Tagung České Budějovice, 8. bis 11. September 1999, Wien 2001, 181-203, Anm. 6). Eine neue Edition eines Großteils der Lieder in: Geistliche Lieder und Gesänge in Böhmen, Bd. II,1: Tropen und Cantiones aus böhmischen Handschriften der vorbussitischen Zeit 1300-1420, hg. von HaNs Rothe, bearb. von BrigitTe Böse/Hans SCHäFER (Bausteine zur Geschichte der Literatur bei den Slaven 29/II,1), Köln etc. 1988; Geistliche Lieder und Gesänge in Böhmen, Bd. II,2: 1420-1475, bearb. von Brigitte Böse/Hans Schäfer (Bausteine zur slavischen Philologie und Kulturgeschichte, Reihe B: Editionen, Neue Folge 14), Köln etc. 2000. Zur Gattung Cantio: Jaromír Černy, Art. „Cantio“, in: $M G G 2$, Sachteil 2 (1995), 389-393.

80 Gisela Kornrumpf, „Eine Melodie zu Marners Ton XIV in Clm 5539“, in: Zeitschrift für deutsches Altertum und deutsche Literatur 107 (1978), 218-230; Dies., „Ein deutsches Marienlied des 13. Jahrhunderts, eine Cantio - und eine Minnelied-Melodie?“, in: Rudolf Bentzinger/Ulrich-Dieter Opitz (Hgg.), Fata Libellorum. Festschrift für Franzjosef Pensel zum 70. Geburtstag (Göppinger Arbeiten zur Germanistik 648), Göppingen 1999, 101-112; DiEs., „Deutschsprachige Liedkunst und die Rezeption ihrer Formen und Melodien in der lateinischen Lieddichtung des Mittelalters", in: Michael Zywietz/Volker Honemann (Hgg.), Gattungen und Formen des europäischen Liedes vom 14. bis zum 16. Jahrhundert. Internationale Tagung vom 9. bis 12. Dezember 2001 in Münster (Studien und Texte zum Mittelalter und zur frühen Neuzeit 8), Münster etc. 2005, 111-118; DiEs., „Ein unbe- 
überliefert, so dass hier auch für melodische Analysen Material zur Verfügung steht. ${ }^{81}$ Überlegungen zum Komplex Melodie und Gattungszusammenhang wären nicht nur für die hier behandelte Frage nach der Rezeption der Mönch-Lieder aufschlussreich, sie könnten auch dazu beitragen, unser Bild unterschiedlicher Liedtypen und ihres Gebrauchs in unterschiedlichen soziokulturellen Zusammenhängen im Spätmittelalter weiter zu differenzieren. ${ }^{82}$

Der zweite Komplex weiterführender Fragen resultiert aus der konstatierten Diskrepanz zwischen dem vorstellbaren Gebrauch der Lieder am Salzburger Hof und dem, der in der ersten Hälfte des I 5. Jahrhunderts erkennbar ist. Wenn man nach Ursachen dafür fragt, lassen sich mehrere Überlegungen anführen. Präsentation von Kunstsinn, Bildung, Vornehmheit und damit die Sicherung des Führungsanspruchs dürften vor allem dann besonders gut funktioniert haben, wenn es sich um Lieder handelte, die an eben diesem Hof und für ihn gemacht waren. Außerhalb ihres primären Rezeptionskontextes konnten sie in dieser Weise nur eingeschränkt verwendet werden. Zudem dürften, soweit man es überblickt, volkssprachliche geistliche Lieder ohnehin nur selten zum Zweck höfischer Repräsentation verwendet worden sein. Der Salzburger Liederhof war also wohl eine Besonderheit, die keine Nachahmer fand.

Als dritten Aspekt darf man vielleicht den generellen musikalischen Wandel in Betracht ziehen. Die mehrstimmigen Experimente des Mönchs sind im Korpus die Ausnahme, der Normalfall ist das einstimmige Lied. Einstimmigkeit war in den I $380 e r$ und I $390 e r$ Jahren im deutschsprachigen Raum wohl die Norm für musikalische Lyrik. ${ }^{83}$ Dagegen breitete sich in der ersten Hälfte des I 5. Jahrhunderts die artifizielle Mehrstimmigkeit immer weiter aus. ${ }^{84}$ Sie wurde in dieser Zeit wohl zum Normalfall eines Komponierens, das auf musikalisches Können und Wissen Anspruch erheben konnte, dessen Produkte unter Beteiligung der Schrift entstanden und in schriftlicher

achtetes Minnelied in Böhmen und Schlesien. Zu Text und Melodie“, in: Ralf G. Päsler/Dietrich Schmidtкe (Hgg.), Deutschsprachige Literatur des Mittelalters im östlichen Europa. Forschungsstand und Forschungsperspektiven, Heidelberg 2006, 321-337.

81 Mit dem Verhältnis der lateinischen stolligen Cantio zu den Liedern des Mönch-Korpus setzt sich meine soeben an der Universität Basel abgeschlossene Dissertation auseinander.

82 Vgl. Nicole Schwindt, „Musikalische Lyrik in der Renaissance“, in: Hermann Danuser (Hg.), Musikalische Lyrik. Teil 1: Von der Antike bis zum 18. Jahrhundert (Handbuch der musikalischen Gattungen 8, I), Laaber 2004, I37-200; Reinhard STrohm, „Fragen zur Praxis des spätmittelalterlichen Liedes“, in: Trossinger Jahrbuch für Renaissancemusik 1 (2001), 53-75.

83 Wachinger, Textgattungen und Musikgattungen (wie Anm. 28) weist darauf hin, dass für den Mönch und Oswald von Wolkenstein Mehrstimmigkeit „nicht die nächstliegende Wahl beim Liedermachen“ (405) war.

84 Vgl. Reinhard Strohm, The Rise of European Music 1380-1500, Cambridge 1993, 127-196 und 333339. 
Form festgehalten wurden - andere Arten von Musikschaffen hat es parallel dazu sicher weiterhin gegeben. Was nun den Anspruch an kunstgemäße Musik angeht, hätte in einer solchen veränderten Situation ein auf Repräsentation zielendes Musizieren sehr wahrscheinlich mehrstimmig sein müssen. Der festgestellte retrospektive Charakter der Korpushandschriften könnte dafür ein Indiz sein. Die Handschriften aus dem MönchSkriptorium zeichnen auch die Melodien ziemlich vollständig auf: Vielleicht halten sie damit auch eine Art von Musik fest, die entweder bereits verklungen oder aus der einstigen Pracht eines Lied-Zentrums in andere kulturelle Bereiche abgewandert war.

Um solche Erwägungen weiter abzusichern, bedürfte es allerdings eines detaillierteren Überblicks zum Verhältnis von Ein- und Mehrstimmigkeit im volkssprachlichen geistlichen Lied ${ }^{85}$ und dessen Funktionen im I 5. Jahrhundert, wozu der Germanist seinen Kompetenzbereich (noch weiter) überschreiten müsste. Eine umfassende Darstellung der Liedkultur der ersten Hälfte des I 5 . Jahrhunderts wird sich also nur im geduldigen und interessierten Gespräch der Disziplinen erzielen lassen. ${ }^{86}$

85 Das von Kapellen gesungene Repertoire scheint in der ersten Hälfte des 14. Jahrhunderts primär liturgischen Zwecken gedient zu haben und lateinisch gewesen zu sein (musikalisch kunstvolle Ausgestaltung der Liturgie mochte dann wiederum auch repräsentativen Zwecken dienlich gewesen sein), vgl. Sтroнm, The Rise of European Music (wie Anm. 84), 270-287 und 300-307; Martin Ruhnke, Art. „Kapelle“, in: $M G G 2$, Sachteil 4 (1996), 1788-1797. - Eine stichprobenartige Auswertung der bisher erschienenen Bände der Geistlichen Gesänge des deutschen Mittelalters [GGdM]. Melodien und Texte handschriftlicher Überlieferung bis um 1530, hg. von MAx LüTolf, Bd. 1-3, 5 (Das deutsche Kirchenlied. Abteilung II, 1-3, 5), Kassel etc. 2003-2009, erbrachte keine Indizien für höfisch-repräsentativen Gebrauch deutschsprachiger geistlicher mehrstimmiger Sätze. Unter den 536 Nummern der ersten drei Bände (Bd. 5 enthält keine mehrstimmigen Stücke) finden sich 36 polyphone Sätze. Davon sind - nach erster kursorischer Recherche - nur drei in Handschriften aus der ersten Hälfte des 15. Jahrhunderts überliefert (GGdM Nr. 32: A-Iu, ohne Signatur, Oswald von Wolkenstein-Hs. B; GGdM Nr. 407: D-DS 2276; GGdM Nr. 462: D-Mbs Clm 14274, Mensuralcodex St. Emmeram). In keinem dieser drei Fälle finden sich Hinweise auf einen ,repräsentativen' Gebrauchskontext. Auch die späteren Sätze lassen eher an andere Gebrauchskontexte denken, in 29 Fällen ist der deutsche Text mit einem lateinischen verbunden (z. B. In dulci jubilo siebenmal, Ein kint geboren in Bethelehem Puer natus in Bethlehem, sechsmal), was an gottesdienstlichen Gebrauch denken lässt.

86 In diesem Sinn danke ich Organisatoren und Zuhörern der Wiener Konferenz sehr für die Einladung, die lebhafte Diskussion meines Beitrags und zahlreiche Hinweise auf Phänomene und Probleme, die leicht aus dem Blickfeld des Germanisten geraten. Für eine eingehende und kritische Lektüre der Druckversion und hilfreiche Einwände sei Gert Hübner (Basel) sehr herzlich gedankt. 
